\title{
Mindful words: \\ How do our stories change when we read about mindfulness?
}

A narrative inquiry

\section{Julia Watkin}

A thesis submitted to Victoria University of Wellington in partial fulfilment of requirements for the degree of

\section{Master of Education}

School of Education

Victoria University of Wellington 


\begin{abstract}
This narrative inquiry tells the stories of four women who read an online blog about mindfulness for three weeks and shared their reflections of the experience. It investigates the role that reading plays in the development of mindfulness - a process that has not featured previously in the research literature. The women in this study were recruited via social media, and all were motivated to learn more about mindfulness and how it could have a positive effect on their daily lives. Data was collected via questionnaires on their understanding of mindfulness and their state of mind prior to, and following the completion of, the project. The women also submitted written reflections, based on their reading and experience of each blog post. Analysis involved coding the data and forming it into individual narratives, written in their own words. The narratives were then deconstructed to investigate their association to the transformative learning process-perspective, experience, reflection, meaning making, and interpretation. The results showed that the women did, indeed, have transformative learning experiences, although the sustainability of such change needs further investigation. Despite limitations, these stories suggest that reading about mindfulness deserves a higher profile - and that the use of a digital platform to host written mindfulness content has the potential to positively affect a wide audience.
\end{abstract}

Keywords: mindfulness, reading, transformative learning, perspective, experience, reflection, meaning making, interpretation, well-being. 


\section{Acknowledgements}

"May the work of your hands be a sign of gratitude and reverence to the human condition." Mahatma Gandhi

To Mary, Rebecca, Cordelia, and Alana-you are the hearts of this story and your beautiful honesty will always be remembered.

To Barrie Gordon, my patient supervisor-I am forever grateful for your trust and willingness to take this unpredictable adventure with me. We made it.

To the wonderful authors who have transformed my world-your words are my inspiration.

To my family and friends-your love and support of my ever-changing journey is very much cherished. 


\section{Contents}

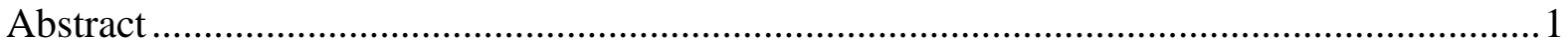

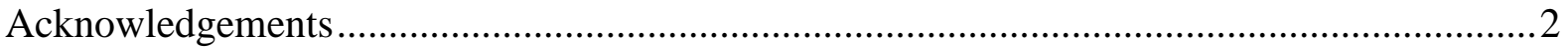

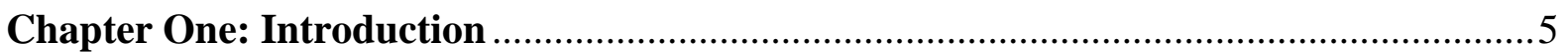

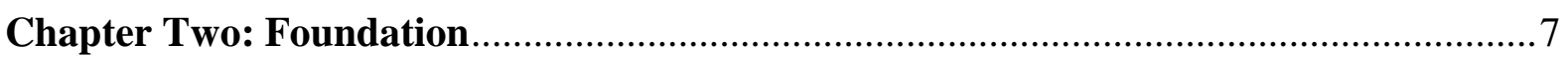

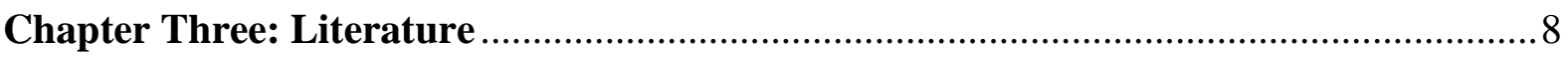

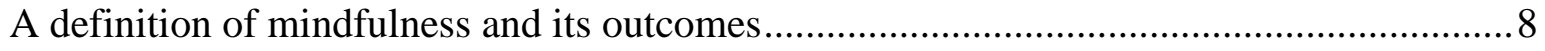

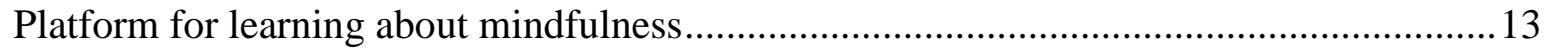

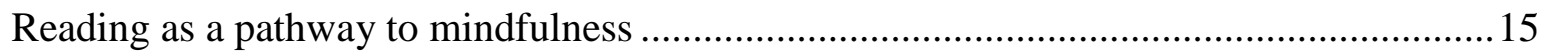

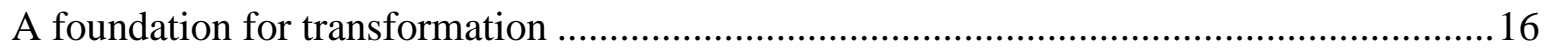

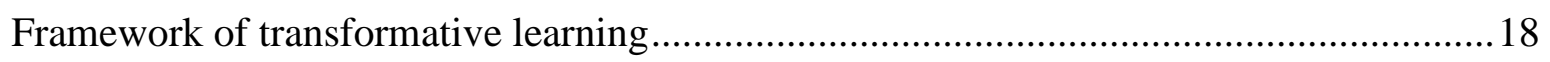

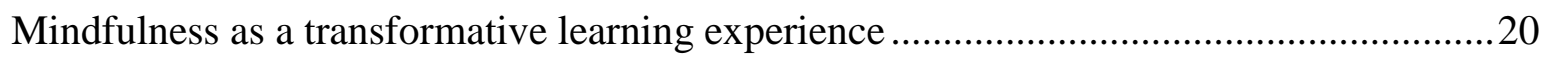

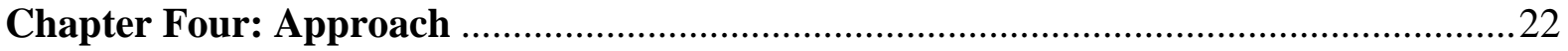

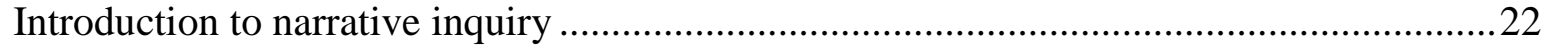

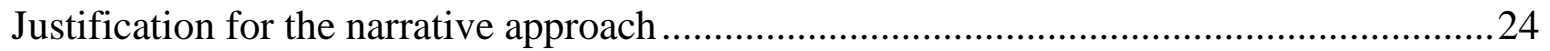

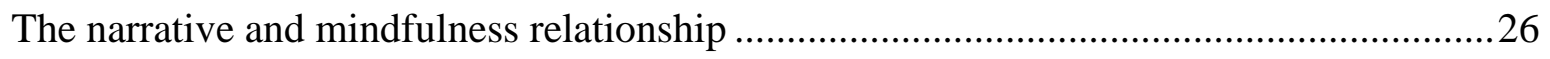

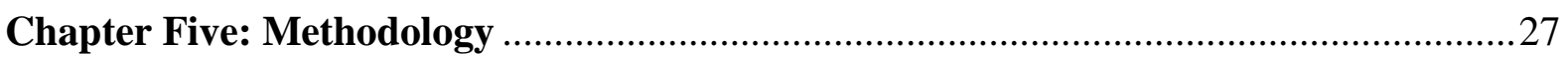

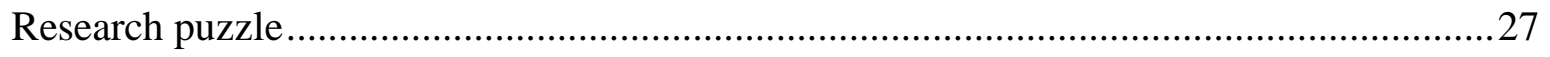

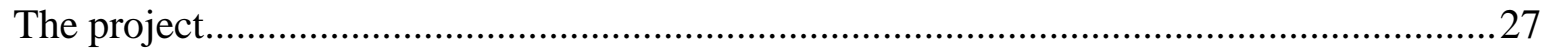

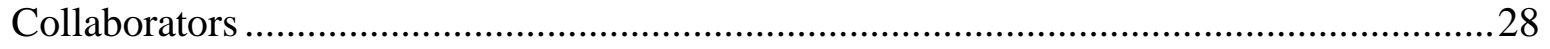

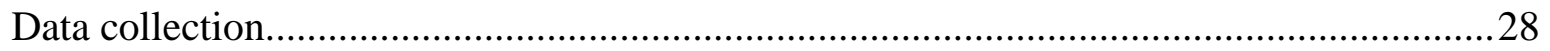

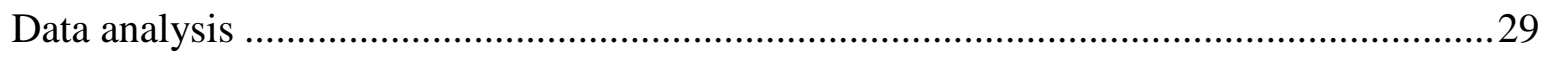

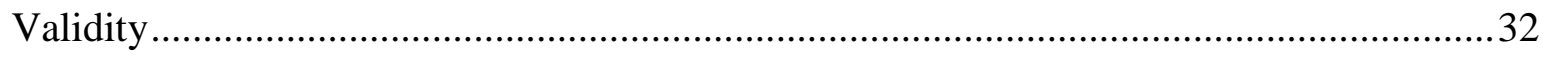

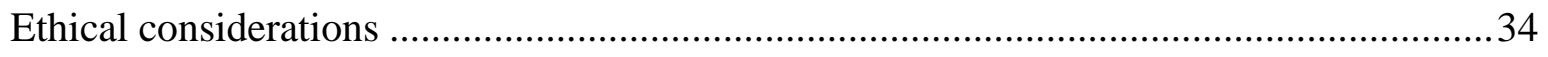

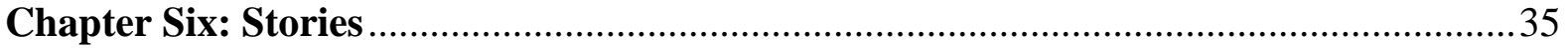

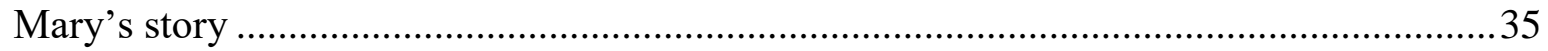

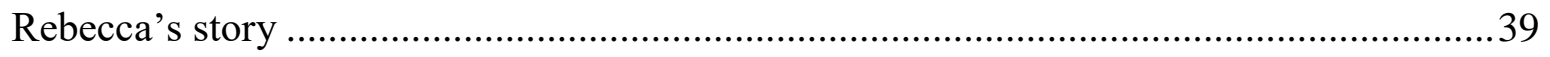

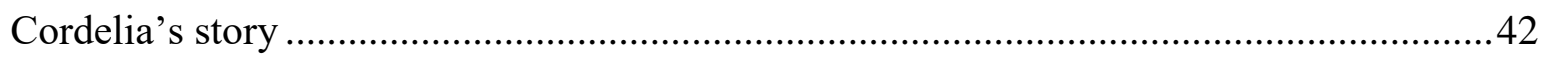

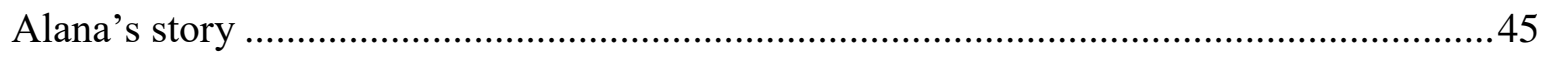

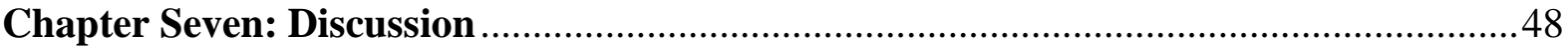

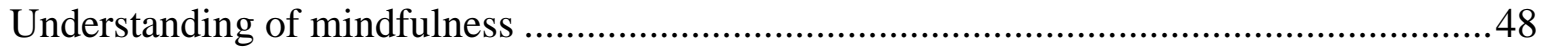

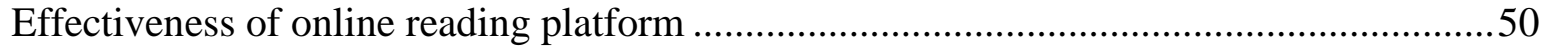

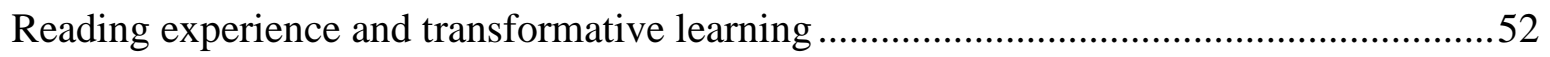


Chapter Eight: Closing words

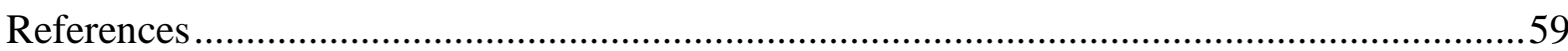

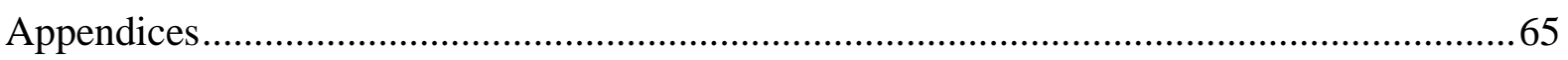

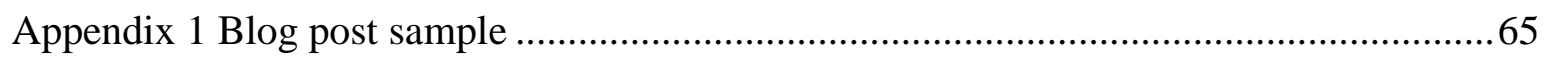

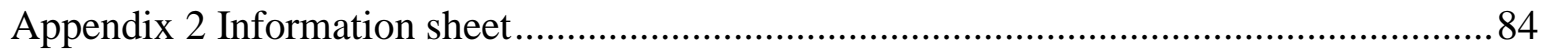

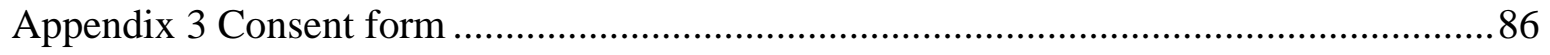

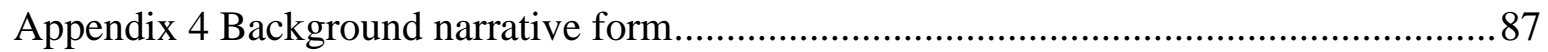

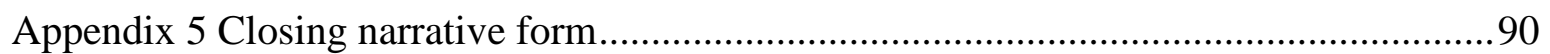




\section{Chapter One: Introduction}

\section{“Every morning we are born again. What we do today is what matters most." Buddha}

A thesis is an intricate mission. Every morning, you are a new person. Every morning, you want to start fresh. But, you have to hold on to what has come before. You have to work your way back through the fields of academia, of literature, philosophy, and methodology, before you can figure out where, how, and why, oh why, to go forward. So, let us first look back - to where this all began. Then, hopefully, this intricate thesis mission, this tricky puzzle of ever-moving pieces, this story of a journey to meaningful, mindful living will make sense to you. To us all.

We join this journey where it began, seven years ago - although she did not know it at the time. We see a young woman, as she was young then-packed full of one-day-hopeswishes-and-dreams. One day, her mind will be content. She will not be anxious and worry about what may be - or beat herself up over what, as is much more often the case, may never, ever be. One day, her life will be calm. She will not be rushing from one nothing to the next, barely noticing a thing along the way. One day, her heart will be happy. She will be present with her loved ones, not constantly distracted or too busy to play or with one eye on the time and one hand on her phone. One day, her moments will be full of meaningful interaction. She will not be working for the pay cheque. She will not be longing for the weekend. She will not be waiting for life to start.

Then, one unremarkable day, seven years ago, this young woman just stopped. An itch, perhaps? She knew that she had to do something because this was getting ridiculous. She was not waiting for her life to start-it had started the moment she took her first breath. She was completely missing the point. Life does not live itself. Life was waiting for her to start. So, she did the best thing she knew how and took herself off to the bookstore for some self-help magic, and that is where she stumbled across an enlightened author named Eckhart Tolle (2005), who wrote of the "flowering of human consciousness" (p. 1). The art of mindfulness. Hallelujah!

So began her journey to discover that this wondrous word could change her ordinary world - change her. Does she still rush by and miss things? Yes - but the rose-smelling moments are becoming more and more frequent. Does she still use a phone? Of course-but 
she lives occasionally with it, not constantly on it. Does worry sneak up on her? Indeed, sometimes - though she has learned to breathe in awareness and breathe out contentment. Inhale deeply, exhale completely. You see, mindfulness is not a silver bullet, nor an oftcoveted end reward. It is a practice, an ever and constant choice- to change how we think about how we live. As philosopher and psychologist, William James, simply said — when you can change your mind, you can change your life.

When the opportunity to write a thesis tumbled across her path, unwittingly, and quite inconveniently, tripping her up, she knew she had a choice. Find a story that had already been told, replicate it, and prove that she could do research - as per the usual Master's rote. Or, she could pick herself up, dust herself off, and go on an adventure to discover how, or if, other people's stories changed when they read about mindfulness-just as hers had done and was continuing to do. To write a thesis that had not been written, nor read, before. And so, we delve into the compelling world of words, the words of the world. We are surrounded by, burdened under, swirling word clouds of doubt, stress, anxiety, boredom, disconnect, depression, and hopelessness. Not surprisingly, our mental health is being suffocated in this negative pressure cooker.

This project aims to flip the switch. If we replace these distressing words with ones of hope, of positivity, of mindfulness, can we change our stories? Change our minds? Change our lives? This project hopes to dispel the myth that to be mindful, one needs to be a meditator. It may be complementary, but not necessary. To me, mindfulness is about the words. Beautiful, simple, liberating words. Brené Brown (2018) calls herself a researcher storyteller. I am going to borrow this turn of phrase and call myself a storytelling researcher. Switch flipped. I wish this thesis to be real, to be engaging for whomever tumbles across its path-or vice versa. I hope it adds to, not only the research literature, but to mindful words, in general.

Our project brought together five women, myself included-all of us with different personality traits, vastly varied backgrounds, and contrasting life situations. The participants - we will call them collaborators, for that is what they are-were introduced to, what became, our special brand of mindfulness. They spent three weeks reading a blog woven of the three main threads of mindful living-present moment awareness, nonjudgement, and purposeful attention (see Appendix 1). They reflected on their reading, their 
individual interpretations of the words before them-words that had turned my world on its head. They reported back on their journeys.

These are their words.

This is our story.

\section{Chapter Two: Foundation}

\section{"Suffering usually relates to wanting things to be different than they are." Allan Lokos}

You may be expecting, nay hoping, to see an overview here? That would, traditionally, be the case. In a thesis. However, this is a story, first and foremost, and if you give away the ending before you even begin, why read — or write — at all? I certainly would not be writing this if I had any inkling what was going to happen - and nor would I be asking you to trudge your way through it. On this journey, we are learning to replace expectation with intention. Intention, curiosity, and just a little bit of blind trust.

As we have mentioned, but it bears repeating, we will not call the participants 'participants', but, rather, collaborators. This conveys the mutual teamwork of this projectwe were not researcher and participants, for I am not really a researcher. I am simply a curious human, sharing experience with fellow curious humans. The outcome of this work will be the combination, the culmination, of five equal hearts, five equal voices.

Though you are not reading a traditional overview, nor a traditional thesis at that, this story will include all the other bits and pieces that you would ordinarily find in a thesis-they may just look, and sound, a little different. There will be a review of the literature, a solid methodology, detailed analysis, and a hearty discussion. The results section will be called our 'Stories' and will feature the collaborators' journeys from prior to the project, throughout the process, and out the other side. The study was designed to answer several research questions — of which we will, hopefully, find sufficient answers. Time will tell.

I have been challenged many times, by others and myself, whether this is thorough research - whether the words I am using, and the way I am using them, are academic enough. I believe that academia, as in life, is what we make of it. I choose to believe more in its wonder and creativity, than its rules and rubrics. I know not any other way of being, of 
writing, of truthfully representing this journey, so I am heartened by the words of Richardson (2000), who says-

"Writing as a method of inquiry ... provides a research practice through which we can investigate how we construct the world, ourselves, and others, and how standard objectifying practices of social science unnecessarily limit us and social science. Writing as method does not take writing for granted, but offers multiple ways to learn to do it, and to nurture the writer" (p.924).

It is my hope that research writing, as we have come to know it, as we have come to be restricted by it, can embrace the spirit of Richardson's words. Before we set off, I would like to say how much I appreciate your time and energy in reading this story-your patience and willingness to leave expectations at the doorstep, and see where it leads. I will take great care in the telling and I hope, I intend, that when you reach our final words, you feel it time well spent.

\section{Chapter Three: Literature}

\section{“Nothing ever goes away until it has taught us what we need to know." Pema Chödrön}

\section{A definition of mindfulness and its outcomes}

The literature on mindfulness, in the research field, is growing ever more abundant, more lush. The focus is predominantly on mindfulness for something, somewhere, or someone. Mindfulness for stress reduction is a significant something (e.g. Baer, Carmody, \& Hunsinger, 2012; Khoury, Sharma, Rush, \& Fournier, 2015), as is mindfulness for chronic pain (e.g. McCracken \& Vowles, 2014; Mun, Okun, \& Karoly, 2014) or other disorders (e.g. Ives-Deliperi, Howells, Stein, Meintjes, \& Horn, 2013; Sng \& Janca, 2016; Wupperman, Ficklang, Klemanski, Berking, \& Whitman, 2013). Mindfulness in the workplace (e.g. Hülsheger, Alberts, Feinholdt, \& Lang, 2013; Leroy, Anseel, Dimitrova, \& Sels, 2013; Taylor \& Millear, 2016) and at school are popular somewheres (e.g. Sibinga et al., 2013; Sibinga, Webb, Ghazarian, \& Ellen, 2016). For those specific someones, there are mindfulness for parents (e.g. Coatsworth et al., 2015), for substance users and abusers (e.g. Goldberg, Davis, \& Hoyt, 2013; Murphy \& MacKillop, 2012; Witkiewitz, Bowen, Douglas, \& Hsu, 2013), for nurses (e.g. Heard, Hartman, \& Bushardt, 2013; Sanko, Mckay, \& Rogers, 2016), or veterans (e.g. Polusny et al., 2015; Stephenson, Simpson, Martinez, \& Kearney, 
2017), to name just a few. While a specific focus on the process of reading for mindfulness appears to be nonexistent, therefore providing our window of opportunity, we can draw on what has come before. But, first - just what is mindfulness? It is up for interpretation, but when I first began researching mindfulness, the definition I returned to, again and again, was this-

"Mindfulness is the awareness that emerges through paying attention on purpose, in the present moment, and non-judgmentally to the unfolding experience" (Kabat-Zinn, 2003, p. 145).

This is a good definition, a thorough definition, one that pops up frequently in the literature (e.g. Burke, 2010; Cavanagh et al., 2013; Tan \& Martin, 2016)—but, what does it all mean? How does it actually manifest itself in daily action? And, most importantly, why should we care? The mindfulness, as defined here, is a combination of -

- Purposeful attention — choosing what you engage with and noticing the world around you.

- Present moment awareness-focusing on right now, not dwelling in the past or worrying about the future.

- Non-judgement-less criticism, more kindness.

When we put these mindful traits into practice, we can provide ourselves with a state of wellbeing, a "positive state of mind and body, feeling safe and able to cope, with a sense of connection with people, communities and the wider environment" (Department of Health, 2011, p. 90). When we are consciously projecting, and protecting, our energy in the present moment, allowing our experience to be, fully, without tainting it with negative or redundant judgements, our state of mind and, therefore, life, can be more positive, more connected, more life-like.

How does mindfulness practice do this? Traditionally, this state of conscious awareness, of mindfulness, has been credited to how it is gained - thus far, this has largely been through meditation (Bergomi, Tschacher, \& Kupper, 2015; Kabat-Zinn, 1994). Meditative practice is sitting, laying, or walking quietly-focusing on the breath to calm the mind and relax the body. This encourages you to be present- there is nowhere else to be. 9 
But, let us make a distinction between mindfulness and meditation-meditation is something we can use, something we can physically and mentally do, to become more mindful, but it is not the whole story. It is not mindfulness, itself. If you are sitting quietly, not doing anything but focusing on your breath, it is, presumably, relatively easy to be non-judgemental - there is nothing to judge. It is relatively easy to pay attention-your only focus is your breath. And, if you have nothing to judge and only your breath to focus on, it stands to reason that it is relatively easy to experience the present moment.

The greater issue is harvesting this mindful non-judgement of paying attention in the present moment — in our real world. This is our why and why our why is so important - the most important. Sinek (2011) talks about putting our why, our purpose, at the centre of all that we do-what we are doing is secondary to why we are doing it, not the other way around. Instead of taking thoughtless action and then asking — why am I picking a fight with my partner? Why am I spending so much time playing Candy Crush? Why am I comparing my body to a mannequin? With mindfulness, we are consciously engaging with the present moment, so before we pick a fight or waste our time or put ourselves down, we can stop and ask - is this really important to me? And, if it is not? We stop. We can take responsibility for, and control of, our own mental health and well-being. And, I believe, reading plays its part here-introducing us to the ideas of mindfulness and why we should be it. Not do it, or make time for it, but be it.

One of the aims of this research is to make the state of mindfulness accessible to a wider audience, so that more people can benefit from its positive influence. This includes less focus on meditation, which has religious associations and begs precious time - time that not many are willing to hand over. However, much to my alarm, Marx (2015) questions the accessibility of secular mindfulness practice-does accessibility detract from, or even completely obliterate, integrity? In his commentary, he understands that, in order for mindfulness-based practices to be accepted in the Western world, any religious implications needed to be removed. Good, we are agreed. And, thankfully, this does not void the practice - he says that the "Buddha was said to have taught 84,000 methods, each tailored to the different aptitudes and capacities of those hearing him" (p. 1153), so a non-Buddhist form of mindfulness should be quite acceptable. But, is acceptable adequate? Marx, both a Buddhist practitioner and a teacher of mindfulness-based cognitive therapy (MBCT; Segal, 
Williams, \& Teasdale, 2001), recognises the benefits of the secular practice, while also questioning everything that is lost in the translation.

Interestingly, while my instinct is to remove meditation to make mindfulness more accepted and accessible, Marx (2015) talks of the overuse of meditation in Western mindfulness - so perhaps it is already more accepted and accessible than I think? The issue he has is that, in Buddhist practice, meditation is secondary to wisdom and ethical conductthe learning comes first and, thus, the context. In secular practice, it is the reversemeditation is used as a tool for change, but without prior learning, that change may not be fully understood or engaged. Marx (2015) says that the purpose of prior understanding is to "build a supportive interaction between meditation and ways of living" (p. 1156). We need to learn about mindfulness before we start trying to incorporate its ways of being into our lives. While Marx would clearly not agree with my setting aside of formal meditation, he may well maintain that the intention of this project is to build a supportive environment from which mindfulness can thrive - to hone in on the power of prior learning, of life context.

Speaking of context, I never thought I would be looking to a study on dishwashing for important information on mindfulness, or anything, for that matter - but here we are, nonetheless. The weird and wonderful mysteries of life. Hanley, Warner, Dehili, Canto, and Garland (2015) performed a control group study on a selection of 51 undergraduate students, in which half the participants read a three-minute descriptive dishwashing brief and the other half read a mindful dishwashing brief, of the same length. The students spoke of their interpretation of the text, the prior learning (Marx, 2015; Mezirow, 1990), and were then timed to wash a set number of dishes, in a controlled environment. Following the chore, the students completed a mindfulness scale and responded to questions about the experience itself-how many dishes did they wash? What did the soap smell like? How long did it take? Despite the brevity of the instruction (Hanley et al., 2015) and, in my experience, the utter mundanity of the task, the students in the experimental group displayed increased positivity and decreased negative affect.

Who would have thought? Why is this important? Though this study involves a little reading, the authors make no mention of the involvement of reading for mindfulness - they are interested in the act of dishwashing cultivating the mindset. They suggest that "an everyday activity approached with intentionality and awareness may enhance the state of 
mindfulness" (Hanley et al., 2015, p. 1101). Really, it is mindfulness-fully embracing experience is mindfulness. This study gives me so much joy. It looks like an unorthodox method of mindfulness instruction can have its intended results, which gives me hope for this project. It is reading-however minor its role, I will take it. It is turning the ordinary, everyday into the mindful - turning living into mindful living. As Hanley et al. (2015) conclude, their students appeared to turn a task that is, for all intents and purposes, an unpleasant chore, and come out the other side with decreased nervousness and a feeling of inspiration. The magic of mindfulness?

But wait, there is more - this beautiful, unassuming dishwashing study has more to give us. Both groups of students washed the same number of dishes in, roughly, the same amount of time, yet the mindful group overestimated how long it took them to do the task. This finding has corroborated data from other studies (Berkovich-Ohana et al., 2012; Kramer et al., 2013) that found changes in time perception, as a result of mindfulness trainingchanges that were associated with improved well-being (Adshead, 2013). Mindfulness, it would appear, increases situational awareness, which slows the passage of time. While we may not particularly want dishwashing to feel like it takes longer than it actually does, this is significant in our rushed, busy, full-to-the-brim daily lives. The slower our perception of time, the more we are paying attention. The more we are paying attention, the more we are actually experiencing life, not blurring our way through it.

How will we know if this project has succeeded? The best way to showcase the general outcomes we are looking for is to report back from experienced mindful practitioners (see Figure 1) - and see if their outcomes match our hopes. Machado and Costa (2015) interviewed and analysed data from 22 such people, who attended weekly mindfulness sessions and had completed an 8-week mindfulness-based stress reduction (MBSR; KabatZinn, 1990) course more than a year previous. The practitioners talked about their motivations and concepts of mindfulness, perceived changes and daily impacts, and difficulties of mindfulness practice. In terms of motivation, participants originally accessed mindfulness practice for the purposes of dealing with stress, anxiety, and maladaptive tendencies - which is pretty standard in terms of what people believe mindfulness is useful for. Following practice, this soon changed to notions of self-care, being a better person, enjoying life. Their concept of mindfulness is noteworthy-they call it a recognition of reality. I would agree-my experience of gaining mindfulness changed what I view as 
important, thus changed my reality, as it had previously existed. A consistent association with mindfulness is also increased well-being and a positive outlook. Participants perceived a significant change in their observations - they became far less concerned with looking to others and, instead, focused inward. They gained a greater understanding of others' actions by understanding their own. Mindfulness gave them the capacity to make conscious decisions, to realise their choices and reactions - in other words, a greater awareness of emotional states of being and regulation of those emotions.

\section{Platform for learning about mindfulness}

Something that bears consideration is that the above outcomes resulted from participation in traditional MBSR training and this project is anything but. Firstly, it is being delivered online — what of that? It is definitely being trialled, but is it effective? A review by Spijkerman, Pots, and Bohlmeijer (2016) looked at 17 different studies, involving adapted MBCT, MBSR or acceptance and commitment therapy (ACT; Hayes, Strosahl, \& Wilson, 1999), delivered via a website, online classroom, or smartphone app. Their meta-analysis showed that the mindfulness-based interventions (MBIs) had small, but still statistically significant, effects on depression, anxiety, and well-being, and had the most promising effect on stress. Perhaps, not surprising, given the fact that mindfulness is most commonly called upon for stress-related treatment (e.g. Baer, Carmody, \& Hunsinger, 2012; Khoury, Sharma, Rush, \& Fournier, 2015). It is important to note the language here-when the authors talk about the effects of these MBIs, they do not talk about the participants' levels of mindfulness - it is the "effects of online MBIs on depression, anxiety, stress, [and] wellbeing (Spijkerman, Pots, \& Bohlmeijer, 2016, p. 108). A positive mention is that the results of the online MBIs on stress reduction were comparable to traditional, in-person mindfulnessbased trainings. These results did include one outlier, but when the outlier was removed, the numbers were still strong. Interestingly, the outlier was a 12-session programme, much longer than the others and begs the question-does length play a part in the effectiveness of online MBIs?

Obviously, this project is only three weeks long and, as yet, I have no idea if that is long enough? Other studies that call themselves 'brief' include Kemper's (2017) research on healthcare staff who completed online mindfulness modules. The three modules were each an hour long - introduction to mindfulness, mindfulness in daily life and mindful breathing 
and walking. Mirroring Spijkerman, Pots, and Bohlmeijer's (2016) review, Kemper (2017) also discovered small, but significant, increases in levels of mindfulness. She told her participants not to count on immediate changes-it is not a magic switch. Therefore, she was quite surprised to see signs of change. The participants in her study were not required, nor expected, to complete all three modules, but she found that those who did the introduction module were then willing to continue, which is a positive sign-that brief training can encourage further practice. As we have emphasised in our blog posts, mindfulness is an ongoing practice.

Cavanagh et al. (2013) also performed a controlled trial of brief online mindfulness training. Their participants were university students, ranging in age from 19 to 51, and they utilised an intervention that was delivered via the University's virtual learning system. The programme included written, audio, and visual material, guided meditations, reflection activities, and was available to students for 14 days. Again, these authors found small improvements in mindfulness scores, which correlated with decreased symptoms of stress, anxiety, and depression. Here is an intriguing intersection - in their review, Spijkerman, Pots, and Bohlmeijer (2016) treated increases in levels of mindfulness as secondary, opting to focus on decreases in negative behaviours, while Kemper (2017) recorded increased mindfulness. Cavanagh et al. (2013) then correlate the two-increased mindfulness leads to decreased maladaptive tendencies. They go hand-in-hand.

\section{Figure 1. General outcomes from mindfulness training}

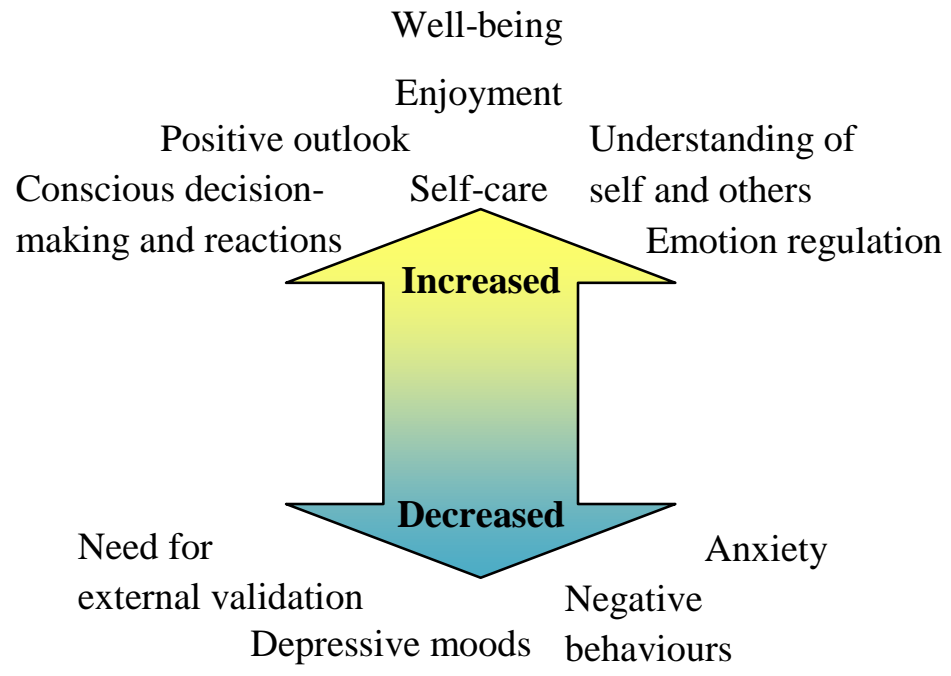

Stress 
Another point made by Cavanagh et al. (2013) is that while they do trust their results, they believe that more research is needed on effect sizes to prove the value of such interventions. And, not just any research-longitudinal research. A brief introduction to mindfulness training may inspire immediate change, but that does not necessarily equate to sustained change. Equally, a brief introduction to mindfulness may have little or no effect at the time, but might incite a spark of transformation down the track. What of these people who participate in a brief online mindfulness intervention, in the name of research? What next? Are they, as Cavanagh et al.'s (2013) study and Spijkerman, Pots, and Bohlmeijer's (2016) review suggest, motivated to continue their own mindfulness journey? Or do they simply lapse and return to life, as it was before? Is there any way we can ensure, as much as is humanly possible, a transformative learning experience in this situation?

\section{Reading as a pathway to mindfulness}

Our most significant point of difference is that our project is looking at reading for mindfulness and, as mindfulness is a state of well-being, likewise reading for well-beingwhich is also expressed as bibliotherapy (Gunning, Richards, \& Prescott, 2011; Hodge, 2016). This involves the use of the written word to understand our minds and overcome our own challenging behaviours (McLaine, 2015). Fun fact- the concept dates back to 300BC when library buildings were ascribed with the words 'medicine for the soul' (McLaine, 2015). Reading is a low-intensity, low cost, but high volume intervention - an intervention that allows for autonomy and increased self-help to overcome apprehension or inability to seek oft-costly professional help (Gunning, Richards, \& Prescott, 2011). While lowintensity, it is also an activity that demands active engagement-what psychologists term an altered state of consciousness (McLaine, 2015). This, not surprisingly, mirrors what mindfulness aspires to achieve here — an altered state of consciousness acquired via reading. A match made in heaven?

To draw on Marx's (2015) emphasis on learning first, reading has always been a core component in education (Hoggan \& Cranton, 2015), so reading to learn about mindfulness seems a given. How does reading teach us so? The reading of fiction, specifically, is said to cultivate humanity through the stimulation of narrative imagination and metaphorical thinking (Lakoff \& Johnson, 1980), increasing the ability to understand others, to recognise their side of the story (Nussbaum, 1997). In a study by Hoggan and Cranton (2015), they 
performed a qualitative analysis on college students' reflections after reading and discussing a short story. Their results indicated that the reading opened the participants up to new perspectives and encouraged critical self-reflection. The participants noted questioning their beliefs and where they come from. Some participants connected their reading with personal experiences, felt emotional reactions to the story, and found role models in the characters. But, it also showed that more participants noted a desire for change than an actual changethis will be a critical factor to consider in this research. It is not our intention just to think about becoming mindful. How can we encourage deliberate, and active, change?

Is it all about a feeling? Wright et al. (2010) wrote on the impact of reading poetry for transformative learning. Just as literature, adults read poetry for insight into the human experience, among other things (Kinsella, 2007). Wright et al.'s (2010) study involved semistructured interviews with 22 self-identified poetry lovers and there was discussion of the physical, emotional, and spiritual connections to the poetry-a real sense of holistic understanding and taking that understanding beyond simply reading poetry, but out into the world and their interactions with it. The participants cite things like a sense of calm, an emotional outlet, opening their mind to question their beliefs about themselves and the world they live in. Poetry reading, they said, was a journey of self-discovery. They talked about making their own meaning, interpreting the words in ways that are different to other people. They were transformed by the words they had read, what those words had invoked especially, specifically, exclusively for them.

\section{A foundation for transformation}

Brookfield (2003) says that to "transform something is to provoke an epiphanic, or apocalyptic, event" (p. 42). This is exactly what we are hoping for here-that the collaborators read the mindful words, proclaim 'hallelujah', and life is never the same again. This comes not from a place of ego, but of experience-I have read things that cannot be unread. Once you are introduced to life-changing concepts that you had never before considered, life does change-funnily enough. But, there are critical factors at play here, beyond simply reading some nice words. Previous life experience, personality type, framework of understanding, willingness to transform, and timing, to name a few. There may be no feasible way to counterbalance these factors and guarantee transformation, but one thing that this study does have going for it is the fact that the collaborators all volunteered to 
take part - they put their hands up to learn more about the potential of mindfulness in their lives. According to King (2009), the opportunity for transformative learning comes about when "the learner is searching for new answers and new perspectives because their prior system is no longer sufficient" (p. 5).

Chopra and Kafatos (2017) introduce the term 'qualia', which is Latin meaning qualities. Qualia is my new favourite word. The authors say that it refers to the quality of our experiences - experiences that are naturally subjective and meaningful. This results from the fact that human evolution has led us to this place of aspiration, where we "seek not just self-improvement but total transformation" (Chopra \& Kafatos, 2017, p. 219). For this total transformation to occur, Dewey's (1938) theory of experience highlights the need for experiences to be connected. He says that, no matter how interesting or positive experiences may be, disconnection leads to discontent. This speaks to our pursuit of mindfulness - the connection between our dissatisfaction of life, as we know it, our choice to seek out a new way of being, and the ever-constant practice of mindfulness. This should, in theory, help to connect the experiences of our collaborators and, thus, create transformation that is constructive and enduring. In theory. However, Dewey also adds that, beyond the time continuum, continuity is also about having a solid plan-subject matter, instruction, and organisation that leads to a result. A purpose. Our stories will tell the tale here. We had a clear plan that was put in place and a group of collaborators who were keen to have a meaningful experience. One of our big questions here is the method of delivery.

Dewey (1938) says that, while education occurs via experience, it does not mean that all experiences are educational. Reading is, of course, a learning activity, but reading a blog? Perhaps, the format is seen as too casual? Not especially informative? Another of Dewey's (1938) words is - discipline. I do not think this is a word that is necessarily associated with online reading material and I certainly did not try to instil it in the collaborators. The posts were made available online and emailed daily with the instruction that they could read at their leisure. So, how can we affect this transformational shift? Can we affect this shift? Of course, the reader's state of mind and openness is a significant contributing factor, but we must also consider the writer and their material-material that needs to be focused and delivered in a specific manner (Gunning, Richards, \& Prescott, 2011). If we are considering material specifically for the benefit of well-being, often a cognitive behavioural therapy (CBT; Beck, 1967) approach is incorporated with worksheets, journaling, and step-by-step 
instruction (Gunning, Richards, \& Prescott, 2011). This is what we have endeavoured to produce here - a blog that was very specifically structured (see Figure 2).

Figure 2. Blog programme outline

\begin{tabular}{|c|c|c|c|c|c|c|}
\hline SUN & MON & TUE & WED & THU & FRI & SAT \\
\hline $\begin{array}{c}15 \text { OCT } \\
\text { Intro } \\
\text { Background }\end{array}$ & $\begin{array}{c}16 \text { OCT } \\
\text { Intro } \\
\text { Mindfulness }\end{array}$ & $\begin{array}{c}17 \text { OCT } \\
\text { Intro } \\
\text { Gratitude }\end{array}$ & $\begin{array}{l}18 \mathrm{OCT} \\
\text { Rest day }\end{array}$ & $\begin{array}{c}19 \text { OCT } \\
\text { Awareness } \\
\text { Pace }\end{array}$ & $\begin{array}{c}20 \text { OCT } \\
\text { Awareness } \\
\text { Worry }\end{array}$ & $\begin{array}{c}21 \text { OCT } \\
\text { Awareness } \\
\text { Quiet focus }\end{array}$ \\
\hline $\begin{array}{l}22 \mathrm{OCT} \\
\text { Rest day }\end{array}$ & $\begin{array}{c}23 \text { OCT } \\
\text { Non- } \\
\text { judgement } \\
\text { Kindness }\end{array}$ & $\begin{array}{c}24 \text { OCT } \\
\text { Non- } \\
\text { judgement } \\
\text { Simplicity }\end{array}$ & $\begin{array}{l}25 \text { OCT } \\
\text { Non- } \\
\text { judgement } \\
\text { Choices }\end{array}$ & $\begin{array}{c}26 \text { OCT } \\
\text { Rest day }\end{array}$ & $\begin{array}{l}27 \text { OCT } \\
\text { Attention } \\
\text { Intention }\end{array}$ & $\begin{array}{c}28 \text { OCT } \\
\text { Attention } \\
\text { Engagement }\end{array}$ \\
\hline $\begin{array}{l}29 \text { OCT } \\
\text { Attention } \\
\text { Care }\end{array}$ & $\begin{array}{c}30 \text { OCT } \\
\text { Rest day }\end{array}$ & $\begin{array}{c}31 \text { OCT } \\
\text { Unity } \\
\text { Connection }\end{array}$ & $\begin{array}{l}1 \text { NOV } \\
\text { Unity } \\
\text { Value }\end{array}$ & $\begin{array}{l}2 \text { NOV } \\
\text { Unity } \\
\text { Action }\end{array}$ & $\begin{array}{l}3 \text { NOV } \\
\text { Rest day }\end{array}$ & $\begin{array}{l}4 \text { NOV } \\
\text { Onward } \\
\text { journey }\end{array}$ \\
\hline
\end{tabular}

Prior to the beginning of the project, the collaborators were sent a background narrative questionnaire to complete (see Appendix 4). It included questions about their understanding and practice experience of mindfulness, their reading habits and feelings about the content they were engaging with, and an open forum to express who they are and their current life situation. The first blog post outlined the posts to come, so the collaborators knew exactly what was on the way and what was expected of them (Gunning, Richards, \& Prescott, 2011). The structure of the posts built in a conscious way-from outlining our definition of mindfulness and laying a foundation of gratitude, through present moment awareness, non-judgement, and purposeful attention, and finally how those three elements culminate in a sense of well-being and engagement in daily life. The posts also included guided questions and reflecting in a journal format.

\section{Framework of transformative learning}

In the construction of this material, and the overall experience, we are attempting to utilise reading as an experiential tool to grow mindfulness - and to increase our hopes of success, we draw on the framework of transformative learning to guide us toward our desired outcomes. According to Mezirow (1990), there are five key steps to transformative learning-perspective, experience, reflection, meaning-making, and interpretation. Let us unpack our understanding of these terms, particularly in relation to this project- 
- Perspective-the platform from which we experience the world and our understanding of it. Mezirow (1990) says that perspectives are largely "uncritically acquired in childhood through the process of socialization ..." (p. 3). Now, our perspectives of mindfulness were not acquired in childhood because we did not know about it back then-well, ancient civilisations did, but not those of us in the Western world. But, the rest of that statement is likely very accurate here-a lot of our perspectives, not just about mindfulness, are uncritically formed through our interaction with the media, society, and now social media (Brookfield, 2003). We form our values and understanding based on what we see, rather than what we feel.

- Experience - the situations we are going through at any given moment. At every given moment. What is the experience here? Reading a blog about mindfulness. On a deeper level, Mezirow (1990) does go a step further to call it personal experience. We can all go to a concert, live through an earthquake, or read a mindfulness blog, and have completely different experiences of that same activity or event. Kennedy (1990) actually talks about the importance of resisting the societal response and really tapping into our own personal account — which would greatly shift our perspectives, as mentioned above. And, is that not the purpose of transformative learning? Part of the trouble and the intrigue, however, is that while we can control the delivery of the learning experience, we cannot control the reception of it.

- Reflection-Dewey's (1933) definition of reflection involves the critical assessment and justification of our knowledge and beliefs. The key word here being critical and that makes this step vital to developing perspectives that are true to who we are. How we differentiate this step from the next is by saying that reflection is not about moving forward-reflection is looking back. It is the critical recollection of past understanding and whether this new experience changes what we thought we knew. Interestingly, though Mezirow (1990) says that reflection is an important factor in active decision-making, he does not believe that critical reflection can happen immediately. He says that "a hiatus in which to reassess one's meaning perspectives and, if necessary, to transform them" is required (p. 13).

- Meaning-making - after we reflect or, perhaps, simultaneously, we may be creating meaning from the experience with which to move forward. Sometimes this meaning 
is warranted and sometimes - it is not. In fact, it is this meaning-making that can be indicative of our psychological well-being (Graci \& Fivush, 2016) - whether we choose to attribute meaning truthfully and supportively, or we distort meaning or instil meaning where there is none. Mindfulness should, if embraced fully, help us to grow healthy meaning-making practices, leaving judgement and negative biases behind - a realisation of what is really important. Much like reflection, meaningmaking is a step that can emerge over time (Fivush, Booker, \& Graci, 2017).

- Interpretation - this is the step where we do move forward. How have we interpreted our experience and how are we incorporating it into our life, from this moment on? Our reality is what we make of it (Chopra \& Kafatos, 2017; Taylor \& Cranton, 2012) and this is the driving force of this research - this ordinary girl has interpreted mindful words and, thus, changed her world. How do other ordinary people interpret their journey, moving forward?

\section{Mindfulness as a transformative learning experience}

Mezirow (1997) says that "meaningful ... learning requires that new information be incorporated by the learner into an already well-developed symbolic frame of reference, an active process involving thought, feelings, and disposition" (p. 10). This active process is precisely what mindfulness is trying to accomplish — active engagement in life, its decisions, challenges, and experiences. Could it be that becoming mindful is, itself, a natural transformative learning experience? As a result of their study with experienced practitioners, Machado and Costa (2015) broke down perceived steps in the process to mindfulness-

1. The first step was the introduction to mindfulness and beginning to practicegenerally, mindfulness-based activities, such as meditation and breathing exercises. This was a time of following instructions and of only brief moments of mindfulness, as a result of the training sessions.

2. The second step involved more consistent outcomes and the benefits of mindfulness beginning to extend beyond the practice. Participants talked of becoming aware of how they were living and the dissatisfaction that came along with that way of life.

3. The next step involved a deeper connection between mindfulness and everyday living - rather than just mindfulness being associated with well-being, life became 
associated with well-being. People were more comfortable in themselves-less fearful and defensive.

4. The final step to mindfulness was life engagement. The strategies of mindfulness, such as observation, awareness, and non-judgement were utilised in daily life. Participants had made changes in their lives, sometimes a change of job, to honour their greater feeling of responsibility for themselves and the world around them.

If we look at these steps alongside those of the transformative learning process (Mezirow, 1990), we do need to break down the mindfulness process, just slightly-there are five steps to transformative learning and Machado and Costa (2015) identified four steps to mindfulness. The following table (Figure 3) shows how these processes align, by splitting Machado and Costa's (2015) first step in two-introduction and brief practice.

Figure 3. Mindfulness as a transformative learning experience

\begin{tabular}{|l|l|l|}
\hline $\begin{array}{l}\text { Mezirow's (1990) stages of } \\
\text { transformative learning }\end{array}$ & $\begin{array}{l}\text { Machado and Costa's (2015) } \\
\text { steps to mindfulness }\end{array}$ & The intersection \\
\hline Perspective & Introduction & $\begin{array}{l}\text { Our current life perspective } \\
\text { leads us to seek out } \\
\text { mindfulness. }\end{array}$ \\
\hline Experience & Arief practice & $\begin{array}{l}\text { Learning about and practicing } \\
\text { mindfulness is anental and } \\
\text { physical experience. }\end{array}$ \\
\hline Reflection & $\begin{array}{l}\text { When we reflect on the } \\
\text { experience of mindfulness, we } \\
\text { develop a greater awareness for } \\
\text { life, as it is, and how it could } \\
\text { be. }\end{array}$ \\
\hline Meaning-making & Deeper connection & $\begin{array}{l}\text { Attributing meaning in the } \\
\text { "right" places allows us to } \\
\text { create deeper connections with } \\
\text { our thoughts, actions, and } \\
\text { relationships. }\end{array}$ \\
\hline Interpretation & Life engagement & $\begin{array}{l}\text { How we incorporate } \\
\text { mindfulness into our daily } \\
\text { life-turning living into } \\
\text { mindful living. }\end{array}$ \\
\hline
\end{tabular}




\section{Chapter Four: Approach}

“Mindfulness means being awake. It means knowing what you are doing."

\section{Jon Kabat-Zinn}

\section{Introduction to narrative inquiry}

Narrative inquiry really is the most logical choice for this research - the only choice for this research. Its relationship to storytelling is absolute, they are one and the same. The approach is, however, more than simply telling a story-its nuances subtle, intricate, influential. Clandinin and Connelly (2000), who have written extensively on narrative inquiry, consider that Dewey's (1938) theory of experience is at the philosophical core of narrative research. This theory involves two factors that contribute to experience-continuity and interaction. Continuity relates to time, past to present, while interaction refers to the situation. The third dimension that Clandinin (2013) adds to form narrative inquiry is context—social, cultural, and/or institutional. On this journey, we are travelling along a continuum of mindfulness and interacting with the words and ideas we come across - each post, each day, a step from the last. We are most certainly operating in a social vacuum, attempting to shed light on those things we do just because we do them, so that we can bring consciousness and purpose back to daily life. This process is exquisitely summed up by Clandinin (2013)-

"Narrative inquiry is a way of understanding experience. It is collaboration between researcher and participants, over time, in a place or series of places, and in social interaction with milieus. An inquirer enters this matrix in the midst and progresses in the same spirit, concluding the inquiry still in the midst of living and telling, reliving and retelling, the stories of the experiences that made up people's lives, both individual and social" (pp. 17-18).

By utilising the process of narrative inquiry, we are embracing the "messy, complex and contradictory factors at play in human experience" (Inckle, 2010). There are several aspects of narrative to consider, both before and during the research process (Clandinin, 2013)- 
- Narrative inquiries are better suited to research puzzles, than research questions. As soon as I read this, a little light pinged on in my head. This project absolutely is a puzzle of ever-moving pieces. Clandinin and Connelly (2000) talk about the narrative puzzle as one of search and re-search, "a sense of continual reformulation" (p. 124). This mirrors their key terms-

- Living, telling, retelling, and reliving, (Clandinin \& Connelly (2000). In a nutshell, we all live and tell our stories - that is human nature. When a narrative researcher comes along and starts digging, stories are retold — reshaped through the telling and interpretation, the lens through which the stories are being heard. That then shapes the going forward - the reliving with a fresh perspective, understanding, or mindset. Of course, this presumes that change has occurred along the way-reliving can equally just repeat the living that has already taken place. The steps of transformative learning might show us here whether it will be possible to put a structure in place to ensure change happens.

- Research relationships. Narrative researchers, much like any others, need to be mindful that they are entering in the midst of their participants' lives - as well as their own. This requires careful consideration, in terms of entering and exiting the research project. I was fully aware of myself in this process, making the decision not to meet my collaborators before the project, so as not to establish personal friendships that may affect the outcomes. The relationships were cultivated, however, through clear guidelines, and communication that was open and consistent-delivered online, which is a world we are all becoming more and more familiar with.

- Developing research texts. This is the process of taking the collaborators' words and turning them into our research story. There will be several elements to consider - the progress of each individual's story, how they come together to form a cohesive picture, and what does it look like when we apply the lens of transformative learning to the analysis? There is also the transition from interim research texts to research texts (Clandinin, 2013). This is simply the process of member checking-the collaborators will get the opportunity to read over their stories to ensure they are accurately represented and the final story will reflect any edits, as requested. 
- Reason for narrative research. The reason for adopting the narrative perspective is summed up by Stelter (2009)—

"The stories of others can be a bearing compass for the listener or reader, which can help them form and revise [their] own narratives, and through that, make their own way of living (more) intelligible" ( $p$. 146).

This is both the reason for using narrative and for doing the research at all. I believe in the power of story and, more importantly, the sharing of stories to light the way for others. It is my desire for the blog to reach the many and I am interested to see whether there are commonalities in the stories of the collaborators. Can they be representative of the voice of humanity? I know what I am hoping, but I am not completely without sense. Narrative may give voice to people and their experiences, but as Riessman (1993) points out — it is a representative voice coloured by our own subjective interpretation of the words.

As such, we move forward in the manner of co-construction (Gergen \& Gergen, 1988; Stelter, 2009). Chopra and Kafatos (2017) suggest strongly that we co-construct the universe through our senses, and our perceptions of our realities-likewise, co-construction plays a significant role in both transformative learning and narrative research. Our perspectives are built in an interactive environment (Brookfield, 2003) and it is this same shared "meaning and social significance that ultimately shape field texts into research texts" in narrative inquiry (Clandinin \& Connelly, 2000, p. 131).

\section{Justification for the narrative approach}

Justification, in terms of narrative inquiry, is what clarifies the role of the researcher. Clandinin (2013) outlines three justifications to consider when engaging in narrative research — personal, practical, and social justification. Here, I outline my role as a researcher-why I am doing what I am doing.

- Personal justifications - Clandinin (2013) says that it is important to know who you are and why you are entering the research, how it is going to change you and how you are going to attend to the stories, and tellers of the stories. 
Who am I? I am someone who has been transformed by learning about mindfulness and who wishes, more than anything, for everyone to benefit from its mindset. I am open to how this research will change me-I do not intend to pursue an academic pathway, but how the collaborators respond to the process will absolutely guide me forward in my work introducing mindfulness in schools and communities. I will tend to the collaborators stories with incredible care and reverence-I have been so grateful for their time, energy, and willingness to share their lives with me, with us.

- Practical justifications - these concern the active implications of the research. How might the outcomes affect the practices of your collaborators when you come out the other side of your research? Or, perhaps more to the point, how are you drawing on the practices of your collaborators to create a better environment for them?

These justifications are much harder to discern. How might the outcomes affect the collaborators following the research? Obviously, that is what we are trying to find out. The hope is that, like myself, they will become happier, healthier humans. The hope is that they will come away with strategies to reduce the stressors and negative influencers in their daily lives. The hope is that they will be sufficiently motivated to continue down the path of mindfulness, the practice of mindfulness. The reason I hope that these are more than just hopes is that I read their background narratives prior to the project and I included certain content to specifically address their areas of need-more subtly, than blatantly. I will continue to follow up with them to try to ensure that this was not just a slap and dash - that we continually revisit the learning and reinforce its place in our daily thoughts and actions.

- Social justifications - this goes a step further than practical justifications to consider the fundamental changes that could occur as a result of the research. What effect might your work have on research theory or policymaking?

Likely, very little — or none, whatsoever. I am told that Masters' theses do not change the world-as much as I would like to prove that wrong. Nevertheless, I am not lacking in social justification for this project - this research will act as a platform from which I will build a community mindfulness programme. 


\section{The narrative and mindfulness relationship}

When it comes to research, the need for substantive results sometimes outweighs, overlooks, or completely contradicts, the subject matter. In our case, there are a large amount of quantitative studies on mindfulness (e.g. Brown \& Ryan, 2003; Cavanagh et al., 2013; Morledge et al., 2013), but what do the numbers mean? When it comes to mindfulness, experience is the key. A search of 'narrative' and 'mindfulness' surfaces results that are mostly narrative reviews - of which the studies involved are not, themselves, narratives. According to one review by Chapman et al. (2013), the authors did not think that a metaanalysis was possible due to the subject nature of the studies and, therefore they performed a narrative analysis on the findings. I wonder if, perhaps, a narrative review may be a way of extracting qualitative data from quantitative data? Extracting experience from a bunch of, not necessarily meaningless, but feeling-less, data?

One study that has used a narrative analysis for a mindfulness-based project investigated the development of mindfulness in undergraduate students in China. The authors, Wang, Law, $\mathrm{Li}, \mathrm{Xu}$, and Pang (2017), collected journals from 70 participants to discover their experiences of mindful agency coaching, utilising personal reflections to evidence any changes as a result of the intervention. Their participants "portrayed the experience of developing mindful agency as an opportunity for self-exploration, advancement, and growth" (Wang et al., 2017, p. 7). This is an encouraging outcome, but the results here cannot be taken with blanket positivity. Of the 70 participants, only eight journals met the authors' criteria for inclusion in the analysis. The journals had to be complete, coherent, detailed, and highly creative. By these standards, it would be fair to guess that the participants who had written such journal entries would have favourable accounts of the intervention, would they not?

Stelter (2009) had a different focus for his study. Rather than focusing on the positive effects, he aimed to "clarify what happens and how it happens when mindfulness meditation training seems to have a positive effect on specific disorders or on personal well-being in general" (p. 145). He engaged in a narrative inquiry to gain an understanding of his participants' lived experiences using diary entries and interviews. None of the three participants in his study had prior experience of meditation and they were all facing different challenges - and, though the focus was not on the positive effects, they did all have positive 
experiences. Overcoming their challenges through mindfulness involved an understanding that their thought patterns about their experiences were central to their experiencesruminating, dwelling, long-suffering in these challenges only deepens our discomfort. Mindfulness, for these participants, created a shift from rumination to embodied cognition (Stelter, 2009)—not just thinking about attention, awareness, and non-judgement, but doing and being it.

\section{Chapter Five: Methodology}

\section{"It is never too late to turn on the light." Sharon Salzberg}

\section{Research puzzle}

The aim of this narrative study is to understand the stories of the collaborators and how they represent their experiences of reading to gain mindfulness. The questions that build this research puzzle are-

1. What are the collaborators' understandings of mindfulness and do they change as a result of this process?

a. If so, how do they change?

2. What are their experiences of reading for mindfulness?

a. This includes questioning the impact of the blog format used for this project.

3. Do the experiences of the collaborators fit within the framework of transformative learning and why is this important?

a. Likewise, how do the experiences of the collaborators compare to those of the traditional mindfulness practitioners in Machado and Costa's (2015) study?

The project

The project involved a series of blog posts, released over the course of three weeks from 15 October 2017 to 4 November 2017 (see Figure 2). The content was not written by a professional psychologist, life coach, or mindfulness guru. It was written by me and simply a culmination of my journey, drawing together inspiration from many wise guides around the 
world. It was carefully designed to follow the three paths of mindfulness - present-moment awareness, non-judgement, and purposeful attention. The content was bookended with introductory posts on mindfulness and gratitude, and closing posts on bringing all the elements of mindfulness together in daily living - unity. Each post was written to be timefriendly, roughly five-minute reads, and included prompts called 'Muse Views', which loosely guided the collaborators' experiences and reflections, if they chose to follow them.

\section{Collaborators}

Collaborators were recruited via a post on a community Facebook page. They sent an email indicating their intrigue and I responded with the information sheet (see Appendix 2), telling them everything they needed to know to make an informed decision on participation. Eight women responded to the post, with five initially agreeing to take part in the project and signing a consent form (see Appendix 3). We lost one collaborator along the way, due to unforeseen family circumstances. Four collaborators completed the journey. It should be mentioned here that the call for participation was not limited to females, but the respondents were solely female - perhaps the content lends itself more to the feminine mindset? But, that is another research project for another day.

\section{Data collection}

Collaborators completed a background questionnaire (see Appendix 4) prior to the project, which included questions about their current concept of mindfulness, whether they had practiced any form of mindful practice or meditation before, their reading habits and feelings about them, and general questions about their current state of well-being. This also included an open forum to share their thoughts on their life situation. I provided links to the blog posts in an email each morning and regularly asked if the collaborators were well, or had any questions or concerns. The collaborators reflected on each blog post-either by following the prompts or adopting creative freedom to reflect in a way and format that felt authentic to them. At the conclusion of the project, the collaborators completed another questionnaire about their experience (see Appendix 5), which asked questions about whether their concept of mindfulness had changed, whether their reading engagement patterns and feelings had changed, and whether they felt, if change had occurred in their daily life, whether it was going to be sustainable-or not. An open forum for response to the experience was also included. 


\section{Data analysis}

Collaborators could opt to hand write their responses and reflections in a journal or type them in a programme of their choice. Two collaborators chose to hand write, so their material was then typed up and printed to aid in the analysis process. Data sets were prepared by assembling notes in chronological order for each collaborator.

The analysis first involved reading and rereading of the content to develop a familiarity with the collaborators and their stories (Creswell, 2003; Stelter, 2009). The broadness of this approach lends itself to many styles of research, in general, and narrative, especially. The content was "openly coded without having any fixed coding themes beforehand" (Stelter, 2009, p. 148). This was to ensure that I went in to the process with an open mind and considered all the material, without expectation or premeditation. Coding involved two steps - firstly, the identification of open codes from the data and then grouping them into categories (Strauss \& Corbin, 1990). These categories were the five steps of transformative learning, as described earlier (Mezirow, 1990). This grouping allowed for a deeper understanding, a recognition of recurring patterns or reflections that appear out of character, and how the experiences of the collaborators fit into the transformative learning process. The collaborators, themselves, were not aware of this analysis angle-I did not want to influence their experience, but rather discover if their natural experiences would align with the process.

The following step was crafting the analysis into a storyline, a plot of "past, present and future [that] is knitted together" (Stelter, 2009, p. 148) to form a coherent, sincere, engaging narrative. Plot is not something I had ever entertained as part of the research process - it sounds contrived and calculated. However, it is actually a crucial component in creating a tangible story - a story built of the collaborators' own words. Richardson (2000) neatly sums up the writing process-

"Although we usually think about writing as a mode of "telling" about the social world, writing is not just a mopping-up activity at the end of a research project. Writing is also a way of "knowing"-a method of discovery and analysis. By writing in different ways, we discover new aspects of our topic and our relationship to it. Form and content are inseparable” (p. 923). 
The central questions used to develop these stories were-

1. Who is the collaborator?

2. What is their prior experience of mindfulness?

3. What is their motivation for participating in the project?

a. This largely comes down to - what is lacking in their life that encourages them to investigate mindfulness?

4. What is their experience of the project?

a. What content resonates for them?

b. What content or concepts challenge them?

5. What are the collaborator's outcomes?

Finally, we ask - what kind of narrative have each of the collaborators conveyed in their reflections? Gergen and Gergen (1983) outline three narrative structures-progressive, stable, and regressive.

1. A progressive narrative represents positive growth (e.g. reading about mindfulness was amazing and now I feel wonderful).

2. A stable or stability narrative represents no change (e.g. I gave it a go, but I feel the same as I did before).

3. A regressive narrative represents negative impact (e.g. the mindfulness blog was rubbish and now I feel worse than garbage).

The stories that resulted here were a culmination of the collaborators' experiences and the researcher's understanding and analysis of the collaborators' words. Their accounts will each fit into one of the above structures and they will provide the foundation for understanding the outcomes of this research project. 
Figure 4. Example of data analysis

\begin{tabular}{|c|c|c|c|}
\hline Open coding & & Categories & Plot \\
\hline $\begin{array}{l}\text { My understanding of mindfulness is the ability to stay with the present, } \\
\text { focus on the now and become more aware of your inner being, your } \\
\text { surroundings and your reactions/interactions with that around you. }\end{array}$ & Understanding & Perspective & Past \\
\hline I'm finding it hard to read today, my mind is buzzing. & Observation & \multirow{3}{*}{ Experience } & \multirow{6}{*}{ Present } \\
\hline $\begin{array}{l}\text { I felt silly doing it, but it was an interesting exercise and I felt good } \\
\text { afterwards. }\end{array}$ & Observation & & \\
\hline I have to play some soothing music and try to focus on that and breathing. & Practice & & \\
\hline $\begin{array}{l}\text { Is it completely ridiculous or naïve - a couple of weeks ago I would have } \\
\text { said yes, but having now been in a position to take some control over this } \\
\text { - I'd say no it is not ridiculous. }\end{array}$ & Consideration & Reflection & \\
\hline $\begin{array}{l}\text { Isn't it better to know your worries - so you can manage them, rather than } \\
\text { setting them free because what if they don't actually work themselves out. }\end{array}$ & Critical thinking & \multirow[t]{2}{*}{ Meaning-making } & \\
\hline Amazing! I had never put it into this perspective. & Revelation & & \\
\hline For me it's about being reminded of the positives. & View & \multirow{3}{*}{ Interpretation } & \multirow{3}{*}{ Future } \\
\hline $\begin{array}{l}\text { I entered this journey not curious, but not necessarily expecting to gain as } \\
\text { much from it as I have. }\end{array}$ & Effect & & \\
\hline Since starting this journey, I now walk each morning. & Action & & \\
\hline
\end{tabular}


There is no formula, no set of rules when it comes to staking your claim (Riessman, 1993). Validity, such as it is, is really in the hands of the reader and their perspective. However, there are several things I can do, as a storytelling researcher, to state the strongest case that I can-

\section{i. $\quad$ Subjectivity}

In the education of research, we learn that objectivity is the researcher's best friend. However, reality, and all our experiences of it, is a purely human construct and, therefore, subject to interpretation (Chopra \& Kafatos, 2017) and, in the case of narrative, we are dealing with very personal, subjective experiences. So, if we agree that subjectivity is a given, how can we trust it? As Riessman (1993) says-truth does not exist in a subjective world. Each person's truth is of their own composition. Without truth to guide us, we have to put our faith in trustworthiness.

\section{ii. $\quad$ Trustworthiness}

In order to develop trust, the researcher needs to be able to show their rigorousness in handling and interpreting the data collected. Member checking (Lincoln \& Guba, 1985 ) is the most obvious way of succeeding in this-highlighting the process of correspondence with the collaborators, ensuring their stories have been accurately transcribed, understood, and narrated in the thesis. Silverman (2000) adds that data accuracy can be corroborated via other observations. This was not practical within the structure of this study and I preferred to accept the collaborators' stories. This process was not about me questioning their truth-it was about hearing their story.

\section{iii. Persuasion}

A persuasive argument, as outlined by Riessman (1993), includes-

- Claims by the researcher that are backed up by participants' stories.

- Consideration of alternative viewpoints.

- A style of writing that invites the reader's curiosity, engagement, and response. 
How we tell the story is so important and, as Stelter (2009) says, it is our wish "to give the individual participant a strong voice, to let him or her speak directly to the reader in order to enhance the potential impact of the story on the reader" (p. 149). This is why the stories represented are told in the first person - their stories, as told by them, but with the benefit of the researcher's eye to provide coherence and uncover truths they may not have, themselves, recognised in their words (Richardson, 2000; Stelter, 2009).

\section{iv. Pragmatism}

This may not be visible until some time down the track-if at all, of course. How has the research added to the literature and provided a foundation for future work? (Riessman, 1993). This is the first piece, that I know of, that has been written on the subject of growing mindfulness out of reading about it.

\section{v. Quality}

Richardson (2000) has five criteria (the questions are also Richardson's own words) that relate well to the quality of a narrative inquiry-

1. Substantive contribution-does this piece contribute to our understanding of social life?

2. Aesthetic merit - is the text artistically shaped, satisfying, complex, and not boring?

3. Reflexivity-how has the author's subjectivity been both a producer and a product of this text? Does the author hold him- or herself accountable to the standards of knowing and telling of the people he or she has studied?

4. Impact — does this affect me? Emotionally? Intellectually? Does it generate new questions?

5. Expression of reality-does this text embody a fleshed out, embodied sense of lived experience? Does it seem "true"-a credible account of a cultural, social, individual, or communal sense of the "real"?

Writing with an artistic voice is certainly what I am aiming for and what I believe contributes to a story that is emotionally engaging — and not boring. 


\section{Ethical considerations}

Ethics are an important, and carefully considered, part of any research projectespecially so in narrative inquiry. The purpose of narrative inquiry is to understand lived experience, the human story. Researchers and collaborators, alike, are on this journey of understanding and, with understanding, comes change. The narrative researcher must be mindful of the fact that they are inviting change for, not only themselves and their collaborators, but also other people that are in close contact with themselves and their collaborators (Clandinin, 2013). Therefore, the ethics of care (Noddings, 1984) must be central to the researchers' process.

This whole project has been one of mutual respect-we are equals on an unknown journey. Not unknown in terms of the planning, content and ethical issues-the study was granted approval by the Victoria University of Wellington's Human Ethics Committee. The collaborators were shown the project schedule from the get go and everyone was aware of their role in the process. What was unknown is that I am doing research for the first timewriting a thesis for the first time. The collaborators are telling their stories to us and going through this process for the first time. How our stories may change? Unknown. The path of life? Unknown.

To protect the collaborators, several supports were put in place. Firstly (and this may sound counter to support), but I did not meet with the collaborators prior to the project. This was in order to preserve their experience-I did not want to colour their judgement before we had even begun. However, the communication channels have always been completely open. I told them before we started, and continually through the process, that I am an open and honest researcher and they can raise any questions or concerns with me at any time. I sent them the web links daily to the new posts and daily asked how they were getting on. Collaborators were also informed before the project started that, should they experience any distressing thoughts or feelings, that a professional counsellor was aware of the project and on hand to provide support, should they request it—no questions asked.

Further to the ethics of care (Noddings, 1984), the collaborators' identities have been protected in this thesis through the use of pseudonyms and masking other distinguishing information. I have been incredibly grateful for their time, energy, honesty and pure 
openness to this experience-this research does not exist without their willingness to share their stories and our stories are now forever connected. Perhaps, forever changed?

\section{Chapter Six: Stories}

\section{"Everything is created twice, first in the mind and then in reality." Robin S. Sharma}

Here, we invite you to read the stories of the collaborators' experiences, as they participated in this mindfulness project — all the highs, the lows, the aha! moments and ah, no moments. As mentioned above, these stories are recounted in the first person to allow us to see directly through their eyes. Hear their words. Share their journey.

Mary's story

I was a nurse, now a nurse educator, originally from Canada, but I have lived in New Zealand for the past 20 years and definitely call it home. I have a partner and two boys, aged 16 and 12, and our household is busy. In fact, it can all get a bit much-juggling home, children, work, interests, and helping out in the community, but I would not give up a thing. I transitioned into education quite late in life and I am very proud of my achievements. Teaching is my happy place. I love my job and I am always looking for ways to improve what I have to give - to engage my students, challenge them, and inspire their learning.

What drew me to this research was just that — the learning opportunity. Mindfulness intrigues me. I have completed a couple of one-day silent retreats, which were fabulous, but difficult. I have not yet been able to fully integrate the practice into my life-I know it is there, but just out of reach. A significant motivation for me is that I was injured in a previous job and it has left me with a number of permanent constraints that affect my daily life - my energy, balance, pain, and overall well-being. I tried Feldenkrais (a movement and awareness practice) for this reason, but I did not take to it as well as I thought I would. I know that with increased mindfulness, I can learn to slow down, focus on me and improve my wellness by listening to my body-knowing when I need to stop and recharge. From both a physical and mental standpoint, I hope improvement can be found in this experience.

One of our first posts was about gratefulness and I struggled a bit with the angletrying to be grateful for pain and suffering? I think gratitude is the wrong way to look at it. Both as an educator, who turns to knowledge for support, and as someone who lives with 
pain on a daily basis, I prefer to approach it with understanding. We need to understand why the pain exists, its cause, and how we can use knowledge, patience, and skill to help, perhaps not even alleviate the pain, but to identify it and acknowledge that it is not here to hurt usbut teach us.

The avenue of gratitude is, however, something that I have recently begun to focus on in other areas of my life. Struggling with chronic illness and being surrounded by negative interactions, having to wait on specialists to make decisions about my life, gratefulness seems like a way for me to grasp back some control-a chance to focus on decisions that I can make for myself, to enjoy the good, happy, neat, unexpected things that happen to me. It is not easy, I have to dig deep. But, if you had asked me a couple of weeks ago if gratitude was a ridiculous notion, I would have said yes. Now? I say it is tough, but possible and within our control.

Day five of the project is one of the reasons why I am here- to slow it down. I know it is something I need to do, but I am a perfectionist, by nature, and I do not want to let someone else down or not meet my own expectations. Filling our days is obligatory, is it not? I know that I feel guilty if I have some time for myself-I feel like I should be doing something for someone else, putting that time to good use. I am learning-very slowly learning that time for me, like doing this writing now, is a good thing. I do matter. Taking time for myself is as good a use of that time as any. But, I am not quite at the guilt-free selftime stage. Yet.

Just as tricky for me is quieting my mind - my hands and mind are always juggling a million things at once. I am the family mobile calendar, the reminder, chief organiser, and appointment checker. My needs are pushed aside to ensure that everyone else has what they need first-which I know is something that I allow to happen. Perhaps, something I even encourage? I am the one who constantly puts others first, but if you ask me, in this moment, what is important to me? Well, they are. They are important to me. As a mother, how could I even begin to consider putting my needs first?

A word I find crops up again and again for me is - guilt. On day ten, the focus was freeing ourselves. Freeing ourselves of issues that are weighing us down, judgements, worries, expectations. What am I worried about right now? I am behind with the reading. I feel guilty_-guilty that I have allowed this to happen. Guilty that I am not better at managing 
my time. Guilty that I am letting someone down. I do not know if freedom is even possible? It seems as if we would just be snatching that moment to say 'I am free', but quickly rushing on to the next thing, because there really is no time to be free.

There was a sentence on judgement that I completely missed the first time I read it - it says that no matter how much we may judge others, we are only harming ourselves. I think we become so caught up in trying to find fault or passing the blame that we forget to see the damage it is doing to ourselves. And, this does not just include judgement of others-I am the first to judge myself. I am taking the opportunity to really look at who I am, my 'why' and focusing on the positive, over the negative. It is not always possible, but I am aware of it and how I can change.

Purposeful attention is challenging. I think I need this written across the sky-a constant reminder to come back, focus on the now. Not the could have, should have, would have moments, but what is, right now. This is so hard. The affirmations are a good reminder-

Today, I will try my best.

Today, I will be good to myself.

Today, I will be grateful. I will be kind. I will share my love.

'I' seems to be a word that is missing from my vocabulary-it is always hidden under the you, he, she, and theys. It is helpful to consciously choose what I am engaging with - engage with my search for knowledge and understanding. I feel safe in the academic field, this is where I do most of my reading - and mindfulness is guiding me to focus on what I need, though it is a work in progress.

My guilt over self-focus made me jar over the title of the day 14 post, before I even began reading it-'Treat yo' self'. It is suggested that our hearts will speak to us in the stillness - but I am not sure about this. What if we do not let there be a moment of stillness, for fear of what our heart may say? I like the idea of starting the day with a series of encouraging statements-

1. An intention -I will be kind to myself.

2. An affirmation-I am brave. 


\section{A gratitude -I am thankful for community.}

This post also led me to a TED talk by Louie Schwartzberg, which resonated with me. Take the time to slow down, to realise that now is just for now, and then it will be gone. We need to treasure it, notice it, be in it. However, we are creatures of habit, and changing our perspectives can be difficult.

The four key steps to living a mindful life really ring true for me-simplicity, clarity, positivity, and activity. Are they easy to achieve? No. Are they possible? Yes. Decluttering is the most obvious step-but actually doing it is the hard part. Clarity is something that I crave, particularly in the midst of pain and brain fog.

We must put down what we carry, open the door, and then take up only what we need to bring inside. Mark Nepo

I can literally see myself needing to put down a whole bucket load of stuff. Tidying our minds is something we do not think of - we are too busy with what needs to be done and giving ourselves a hard time for what we have yet to do. This series has really prodded my inner self and made me aware of who I am, what I am doing - is it for me or to keep others happy?

The readings really made me delve into my pre-conceived ideas of what I thought mindfulness was - to consolidate that knowledge by both reinforcing and challenging the material I was presented with. I found some of the writing too flippant, which caused me to be annoyed by it, rather than content. I think I was looking for the safety of academia, so I was not prepared for the relaxed nature of the blog posts. I was surprised how some information caught me off-guard and I found it confronting and antagonising - to be engaged in aspects of mindfulness that required me to submit or challenge myself, when I would normally be happy just viewing from afar. And, having read the material, it is not something I can now ignore or disregard.

I enjoyed the questions and how they gave me the opportunity to really think about the content and my perspective of it. Having a regular practice, daily reminders, is what made this effective - my brain had the chance to assimilate and realise this is not so bad, what have we got next, bring it on. In terms of sustainable change, I think this has helped me 
to look at my place in the world, what I let affect me, and how much attention I give to life around me. It has allowed me to allow myself some rest and recuperation time. I just need to remind myself daily that me time is okay-more than okay. It is encouraged. It is necessary.

\section{Rebecca's story}

I have been married for 20 years and we made the move to New Zealand from Wales 10 years ago. I have always suffered from feelings of not being good enough-not pretty enough, not thin enough. My appearance is how I have measured my self-worth and I have just never measured up. I am definitely a perfectionist-I do not like to fail. I get stressed even doing the 5-minute quiz in the daily newspaper. What makes this worse is that I see myself so reflected in my sons, aged eleven and seven - I feel as if I have let them down. Anxiety, low mood disorder, ADHD, autism, OCD, and low self-esteem are just the beginning of what we are dealing with on a daily basis - and I beat myself up regularly and well for it.

I am an introvert who appears to others as an extrovert - but it is all an act. I will not walk into a room full of people and just start talking - I do not believe I am interesting enough. I would love to be at peace with myself. I would love to have the freedom to not worry so much what others think of me. To just be me and be okay with just being me. My understanding of mindfulness is that it brings you back to basics-to your experience in the present moment. It is about taking your focus away from worries, of which I have many, and honing in on what really matters. It centres you.

I do have a little experience of mindfulness-I completed a four-week mindfulness course, held in my community. I thought it was great - at the time. I was motivated to complete my mindfulness practice every morning on the train to work. By the time I arrived, I was in a happier frame of mind, ready to start the day. However, I quickly learned that mindfulness takes practice and consistency. Unfortunately, I did not practice on a regular basis and let it slide - the happier frame of mind went right along with it.

The definition of mindfulness used in this project was a big aha! moment for me. Mindfulness is being present. Without judgement. Paying attention. This makes so much sense. I think I had been so focused on simply being present, but I did not actually want to be present because of what I am present in - the anxiety, the self-criticism, the worry. So, I have 
been pulling away, rather than centring myself. I need to work on the judgement practiceor, more specifically, the non-judgement practice. And that starts with paying attentionpaying attention to the small things that $\mathrm{I}$ am grateful for. It is nice to be reminded that, in amongst all the turmoil of life, there are always things to be grateful for.

I am not surprised that the post about pace left my mind buzzing. I found it really hard to read. I get it, but I forget it just as quickly because my mind is racing. All the time. I think that is pretty common? We are all racing from one place to the next with thoughts racing through our heads a mile a minute. Of course, the thoughts I have are not just idle thoughts - they are worries. Now, the worry post - that really resonated. I loved the line-

Thank you, Worry, but that is enough now. I got this.

It is something we are trying with our six-year-old - to call his worry 'Monkey Moo' and tell it to go away.

What better way to follow than with a day for quieting the mind. I found this message really strong and it helped to calm me down. The section on switching off our phones was particularly powerful for me. I have been using my phone as an escape from having to deal with real life - but it has gone beyond that. I play games while I am watching telly. I have lost the ability to sit for even 30 minutes without reaching for my phone and playing Candy Crush. What have I done to myself? I thought an escape from reality was a good thing, but I want my life back.

I want myself and my community back. The words on kindness, I felt, were written for me. Kindness to self and to others. I do not feel like I have a community anymore. Recently, a long-term friendship ended because I felt strongly about removing toxins from my life and that did not go down well. The friendship turned nasty and vindictive. I feel as if I have lost my sense of trust in people. I do not have anyone to just chat with-and, when I do, I end up feeling guilty for sharing my experiences.

What brings this together is the post on choices. I loved the washing line story-

Do you know what really grinds my gears? And, this is so ridiculous-

Hanging the washing out.

I know, right?! 
We've got a rotary clothes line and when it's windy (hello, Wellington!), it moves every bloody time I go to hang something up.

So. Frustrating!

So ridiculous.

But, on the weekend, as I was about to grumble headlong into the wind-

I just stopped.

Took a breath and smiled.

I do this myself, when I see a Kereru swoop overhead-stop. Take notice. And realise that we are choosing how we react to things. And people. People do not hurt us - we are hurt by people. People do not make us mad-we allow ourselves to become mad as a reaction to what others do. This made a lot of sense. It is a struggle, in practice, but it makes sense.

Bringing the present moment and non-judgement together with purposeful attention is my next step. Finding my 'why'. I have tried to simplify my life lately, to help me cope and find what it is that is driving me. Like I said, removing myself from anything or anyone that I feel is toxic has been an important part of, not only moving on, but moving in an upward direction. Because I know that I have not been in a good place and, while others have not taken the change well, I need to do it for myself and that is important.

I really like the idea of connecting with nature and have reaped its benefits. My husband got made redundant during this project and it has been really difficult to manage and adjust. I was going to cancel my fortnightly horse riding lessons, but that is 90 minutes, without a phone, out in the elements, watching the natural world unfold around me and it comforts me. It centres me. Perhaps, that is part of my 'why'? I know that I do not need facials or expensive meals - but getting out in nature is important and helps me a lot.

For me, this experience has been about being reminded of the positives - the good things, the important things, the little things. It is very hard to be caught up and feeling trapped with negative thoughts - very hard, and all too easy to fall into that mindset. I find that mindfulness is helping my resilience. I liked the opportunity to be reminded every day of something good-you can have the best intentions, but sometimes you just forget or do not have the willpower to be positive. The reminders are key. 
I am finding myself being more conscious of the things I pay attention to. If I am on Facebook, I can see the goodness and joy in what others do, instead of reflecting negatively-not all the time, it is a practice, a work in progress. I really enjoyed the reading - and the length of it was meaningful. Just a line, a motivational quote, and it is gone-but this content was enough to make me reflect and it had a positive, uplifting outcome. The exercises, however, are a different story - they only work for me if I have a timeframe or expectation. Otherwise, I will just forget - say I will do it later and not end up doing it, not want to face up to it. Too hard basket.

During this project, I got excited by the concepts-I felt enlightened. However, much like my previous dip into mindfulness, I am not sure it will last. I benefit from reminders, from support and camaraderie. When you struggle with self-worth, as I do, motivation is hard to muster on a daily basis. But, I will keep trying. I will sit on the train in the morning and reflect. Be still. And mentally prepare for the day ahead.

\section{Cordelia's story}

My understanding of mindfulness? The idea of giving your mind a break from everyday stress and pressure by taking time to focus on your environment, your actions. Or, sometimes, even trying not to think at all. I started doing some mindfulness practice when I was studying web development - the area I now work full-time in. As part of the course, we would practice mindful breathing for two minutes at the beginning of each lesson. When I did further investigation, I found that it is said to be an effective way to combat depression and anxiety, which is a constant battle for me.

I was always a very anxious child and suffered depression during my high school years. I am doing everything that I can now to get my anxiety under control, but I really want to get off medication. I know my life, and my partner's life, would be easier if I did not get so stressed about things that can easily be dealt with—or, equally, by things that I have no control over. I find myself getting stressed about global warming and "leaders" ruining the world. I think that is understandable? All the stress and anxiety is intensified, I know, by trying to get through life too quickly, always wishing for the next thing to come along. I need to slow down and appreciate each day. 
How mindfulness was introduced at the beginning of the project already had me thinking a little differently about it. It is not so much about taking time out-meditating or doing breathing exercises for a few minutes before you return to your regularly scheduled daily stresses. It is, instead, a whole way of being. It is being present, appreciating the moment, slowing down, and keeping perspective. And being grateful. Most days, I will reflect on how lucky I am to have my partner in my life, but I do not have thoughts of gratitude for much else on a regular basis. If I am going through a hard time, I do try to think that it is okay, it could be worse, be grateful—but I am not sure that it helps much. You still have to go through the tough times, regardless.

Slowing down is something I have been told I need to work on and I know it. I feel it. I have often thought that I am missing life by rushing through it, not really taking the time to experience it. I barely remember events that have passed. I took a trip to Spain in 2009 and I really do not remember enough of it. Ironically, I was too busy telling myself to make the most of the experience, that my mind was on overdrive and took nothing in. Simpler questions even get me stumped-how was your week? I do not really know, I can only remember yesterday.

I have tried to have quiet meditation time, as the post about focus suggested silence to clear the mind and reset, but I just could not switch off. It was not so much thinking about the future or what am I going to do about such-and-such, but a reviewing of the day. Or remembering something completely random from months and months ago. When I tried it a second time, it seemed to work better-having a process to work through is helpful. Like, focusing on different parts of the body and sending your breath there. I will keep trying to empty my mind.

Empty of regrets and limiting self-beliefs would be a good place to start. When I was 18, I did not go to art school because I let someone else talk me out of it. A few years later, I thought of it again, but I told myself that I was too late or I was happy where I was. I do often wonder, though — what if I had just tried? Honestly, I do like my job and my life right now, but what ifs are never far away, are they? This statement really resonated with me-

If what we want to do is already being done by someone else ... at least we know it can be done. 
I like this perspective, especially coming from a creative standpoint. My partner says that I am too self-critical and that is why I do not enjoy the things that I make. But, instead of looking at other people's creations and questioning my own talents, I could think, well, practice makes all the difference. And, if they can do it, there is no reason why I cannotand just because they are successful, does not mean that I will not be. I need to have belief in what I can do- - look to others for inspiration and know that I am completely capable.

It is all about choice, right? Like, choosing how we react to things. Or people. There is a co-worker in our office who just will not stop swearing at his computer when he is mad, which seems to be all the time. Can I be grateful to have someone so experienced on the team? Sure, but it does not help much. I realised that I do have a choice how I let him affect me. I can put my headphones on, for one. I can remember that he works slightly different hours than me, so it is not my whole day that is broken with curses. Choice.

And, not only do I get to choose what I react to and how I react to it, but I can also choose what I pay attention to. What is important to me? Going to the gym in the morningwhich is not something our minds or bodies often want to do, but I can remind myself of why I made that choice in the first place. Why I should keep making it. I want to lose weight. I want to get into shape. My family medical history means that I need to be actively interested in my health. Not to mention the fact that natural endorphins are good for managing anxiety.

When the focus becomes what is truly important, it also helps to weed out what is really not important. Mindlessly scrolling through Facebook? Not important. I have pretty much completely ruled that out over the last few months-worthless rubbish. I do use Instagram a lot - partly for inspiration, to follow web comics and artists, and for cute puppy pictures. It is my me time. As part of the self-care post, I did write a letter to myself. I felt really silly doing it, but it was an interesting exercise and I felt good after having done it.

An accomplishment, maybe? A little self-acknowledgement goes a long way? I have tried to de-clutter my home several times, but I find I am too attached to too many things. The things that I do put aside to get rid of, then seem to stay there for months because I just do not get around to taking them to the charity shop or the dump. My life is an endless stream of "I have not gotten around to it yet." 
In reflecting on this experience, I see that mindfulness is more than I originally thought. It is an important tool for training your mind to think in a kind way, kinder to yourself. I am not sure I am quite there yet. I have, occasionally, stopped being so selfcritical — not often, but it is a start. I know that I am too hard on myself - trying too hard to be mindful? When I try to switch off, my mind just will not stop. I need to realise that this is okay - be kind. Be gentle. Find what works for me-maybe I have to play some soothing music and use that to help focus more on breathing and less on mind chatter?

Now that it is summer, I can go out and enjoy the nice weather. I love walking to the nearest park and sprawling on the grass - just listening to the quiet around me or looking at the distant buildings. They are my lunch time chill sessions. I definitely appreciate how nice our city can be. That, and a good book.

\section{Alana's story}

I am married to a wonderful man who, for better or worse, understood my crazy mind long before I ever did. I had an extremely dysfunctional upbringing, which left me vulnerable to a very abusive relationship in my early teens. For five years, I suffered horrendous abuse of every flavour, and that led to crippling anxiety, dissociation, and a diagnosis of post-traumatic stress disorder (PTSD). Despite my struggles, I became a teacher, which was my dream since I was five-years-old. I have recently had to leave my home and job to care for my parents full-time and, while I am happy that my dad's life has improved, I do not hold positive feelings toward my mother. If not for my husband and our fur children, I do not know where I would be today-I enjoy them immensely.

Mindfulness, as I was taught during Gestalt therapy, is about remaining in the moment on a conscious level, and understanding that there is no correct or incorrect way, when it comes to your thoughts. I do practice occasionally now-in my mind, I go to a serene place and breathe deeply, until I feel better able to cope with whatever stressful situation I have found myself in. I was drawn to this research project, as I understand the importance of living mindfully, but reinforcement is a key part of the process.

Our mindfulness is not about shutting off our thoughts—in fact, no mindfulness is about shutting off thoughts, nor controlling them. It is about separating 
from them, realising that we are not our thoughts-it is about observing and understanding them.

I think the description of mindfulness used in the introduction to the project pretty closely matches my perception of it. I was not expecting the post to be so easy to read, amusing and poignant-I am certainly excited for this journey! When it comes to gratitude, however? I can honestly say that, most days, I feel despair and fury, rarely gratitude. I think it is a fabulous notion, but possible for me? On a daily basis? I would need to hand over a lot of hate, rage, and disappointment for how my life, however blessed, has turned out. All the wrongs perpetrated against one who was so pure, once upon a time-to give myself over to a daily dose of gratitude may, perhaps, be a miracle?

Less a miracle is a new perspective on worry-wow! This really resonated with me-

So, worry is only ever for the future unknown — and, at the time of our worry, we do not even know if what we are worrying about is ever going to happen, right?

Most days, I ask myself why I am putting my life on hold for someone I think so little of? And I spend almost every waking moment worrying, thinking, over-thinking - the inner voice rarely stops, though is bliss when it is muted! Yet, I am beginning to realise that the things I have stressed myself over - they were all fine! No issues, no problems, they were all easily dealt with. Amazing, I had never put it into this perspective before. I am going to try and not sweat the small stuff. I am going to ensure that I find time each day for me-for the gym, for the sunshine, for time with my beloved. Since I took over my parents' care, I have found myself really needing a nap each afternoon-a break from people, electronics, expectations and responsibilities. Quiet time-it really is a necessary coping strategy.

The judgement element of mindfulness requires more work. I have a colourful history of dropping very deep down the rabbit hole and maintaining my own mental health, whilst focusing so much on the care of others, is especially difficult. I can admit that I am terribly judgemental-I have a big heart, but I do not forgive easily. Or ever? And, I know that my judgements become worse, the more that I have to deal with on a daily basis. Do they serve me? Sometimes - they can help me feel better about myself, in the short term. But, 
realistically? I know that being judgemental does not help me, it just makes me feel like a bad person — which is also a judgement. Ironic.

The post about choices could not have come at a better time-

What felt good? The tense frustration or anger?

Or was the calming acceptance, gratitude, the wonder or wonderful joy a more

pleasant experience?

If we can, just in this short game, choose what we feel about something or

someone-why would we ever choose the negative?

Only yesterday, I became absolutely furious about something so little and my husband told me that I do not have to let them affect me like this. And, then this post came along and it just cemented it for me. I can choose to let it go. I want to be a happy, healthy version of myself-I want to choose that for myself.

Treat myself-now that is a concept. My 'Dear Me' letter starts like this-

\section{Dear Alana,}

Please remember, you are not to blame for all that happened to you. You are kind and what you have given up to care for others is amazing-own it! Forgive yourself for the days that you do not behave as you should.

Since starting this journey, I now walk each morning. My best friend drives past me each day and I never even notice him — and I am thinking if I miss him, I sure am missing out on a lot! I am going to make more effort to stay in the moment, to take notice. To care for myself and begin to repair the relationships in my life that have been lost along the way. Maybe, if I approach them in a more positive, mindful way, they may prosper again? A scary thought!

But, I do want that. I want to be a mindful carer, to be calm and positive. I want to be a mindful wife for my amazing and long-suffering husband. I do not want to be the crazy, angry, mad, mindless, soulless freak that I have allowed myself to disintegrate into! I now know that I can choose-awareness, non-judgement, patience. I believe that you can become mindful by reading about it. I still have dark days, but there are many more light days now, too. 
I entered this journey curious, but not necessarily expecting to gain as much as I have. I was in a pretty sad, dark, angry space and I do not think I actually realised just how bad it was. I was definitely struck by what I read-some days, I would be in such a bad mood and then I would sit down, read the blog and wow! Since realising that what I engage with shapes my experience and what I feel about it, I find myself reading more books and spending less time online - which is a much better way to spend my free time. Facebook and online news leaves me feeling anxious, angry, outraged, and happy, in equal measure-but I sure adore getting lost in a good book.

I am thinking more clearly and calmly, and have begun the arduous task of decluttering my mind-which, I am sure, resembles that of a hoarder's home! I am also

exercising more-I go to the gym most days and for a walk in the afternoons. I usually fit in a nap. All of these things make everything, life, so much more manageable. I hope they will be sustainable. I lost sight of my health for a little while, but I am determined to keep it up.

\section{Chapter Seven: Discussion}

\section{"Life will give you whatever experience is the most helpful for the evolution of your consciousness. $>$ Eckhart Tolle}

What can we learn from the stories of these four courageous, honest women? There are three things for us to ruminate over - which is ironic, as mindfulness is about stamping out so much of our harmful, time-consuming, self-berating rumination. None the less, this will be productive rumination on how their understanding of mindfulness changed, the effectiveness of the online reading platform, and exploring how, or if, their experience fits into the framework of transformative learning.

\section{Understanding of mindfulness}

The first question of this research puzzle was whether the collaborators' definitions of mindfulness would change as a result of the experience. Why is this important? As Marx (2015) emphasised, the foundation of knowledge from which we practice mindfulness is so crucial. If we are going to live mindfully, we want to be mightily sure that we know what mindfulness is - to most effectively experience its benefits. I am not suggesting that the definition I have used here is the only definition—or the right definition, even. However, the 
vague societal view is not of any use to us (Brookfield, 2003; Kennedy, 1990). As part of our definition, I made sure to feature-

Our mindfulness is not hocus pocus, airy fairy-ness. It's not about spending hours meditating or floating off to la la land. No disrespect to meditation or la la land-they definitely have their place, it's just not here.

Our mindfulness is not about changing our lives and becoming commune-living gypsies or spiritual gurus. Again, no disrespect. But, I think there can be a misconception that mindfulness is a bit hippy-dippy, softly-spoken, I can't think of a better term than airy fairy, so I'll use it again!

I asked the collaborators if there was anything in our definition that they were expecting and Mary said just that — she expected comments about mindfulness being airy fairy and hippydippy. That is what is out in the mainstream world and could not be further up the creek.

Our mindfulness was also outlined as-

Trying not to think so much of the past or future and live now, fully awake (but sleeping well!) and making conscious choices.

It means trying to always be kind to ourselves and others-both in our heads and out loud. Trying not to judge books by their covers or react impulsively.

It means trying to live simply, with values at our core, and just making the most of our time.

You'll notice there's a common theme here-

Trying.

Mindfulness isn't a magic switch and it's not a constant energy.

It's a practice.

The collaborators all found mindfulness to be different from their past understanding of it. Mary had attended two silent retreats where sessions included focus and listening to 
your inner being. She found the readings of our project really made her think about her preconceived ideas and was confronted by areas of mindfulness that took her out of her comfort zone-such as the value of self-care, an oft bottom-of-the-list priority for many mothers. Alana came into the experience with the notion that mindfulness was about our relationship with our thoughts and that remained the same-though, the thoughts she was relating to shifted more from negative toward positive. Rebecca and Cordelia both thought of mindfulness as a tool to break, temporarily, away from stress and worries, to get out of your head and focus on the physical happening of right now. They each came away with slightly different views, which reflects the fact that you gravitate toward what you need, at the time. Rebecca saw the experience of mindfulness as being reminded of what is important, to focus on the positive, rather than dwell in the negative. Cordelia realised that mindfulness is not about taking time out, but actually a whole way of being that involves training your mind to think in a kinder way_especially kind to yourself.

Why did their opinions of mindfulness change during this experience? I think because their previous experiences were independent of "real" life. Going to retreats, mindfulness courses, and therapy are all beneficial, in their own ways, but it is teaching and learning in isolation, and you are not necessarily going to be able to apply what you learn in your regular daily living. Rebecca mentioned "completing" her mindfulness at the start of her day, which is contrary to our consistent practice. As Dewey (1938) would sayconnection is key. The project, here, was smack dab in the midst of regular daily livingthere was no escaping it. Hanley et al. (2015) also concluded that practicing in real time might help to integrate the state of mindfulness into daily life. Much like their dishwashing study, our content was concerned with shifting our living to mindful living, with examples of hanging out the washing, eating breakfast, and our use of digital devices.

\section{Effectiveness of online reading platform}

So, it would appear that reading reshaped the collaborators' views of mindfulnessbut, just how effective was the platform? There are three aspects of the online blog format for us to consider - style, structure, and accessibility. In terms of style, the reviews were mixed. Casual is the general character of blog writing and reading, and this character was utilised to try and encourage an emotional connection to the content, much in the same way as poetry elicits a human response (Kinsella, 2007; Wright et al., 2010). Alana was surprised 
by how easy the opening post was to read and it left her even more excited for the journey ahead - by the end, she had gained far more than she had expected. Rebecca made comments like "Wow, this was written about me!," responding to the personable nature of the posts. She also thought the length of the posts allowed them to be more uplifting than a brief motivational quote - they encouraged greater reflection. For Mary, the response was quite different - she was looking for academic content, which is more familiar and trusted to her. She thought the writing style was, at times, too casual and that caused her to switch off from the message of certain posts.

This highlights that different personalities are going to relate to the content differently and, while I would not choose to change the writing style itself, it is important to strongly consider how it is packaged-here, we talk structure. Again, blogs are very fluid and not necessarily written or read with any strict regularity - which is obviously in contrast to Dewey's (1938) discipline for learning. For the purposes of this project, the blog was very specially crafted and the posts were released in pre-determined sequence (Gunning, Richards, \& Prescott, 2011) - but, while the writing was controlled, the reading was not. I did not set deadlines or have specific expectations of the collaborators beyond general reflection and, in hindsight, this may have an impact on how deeply the content was received and considered. For example, Rebecca mentioned that she bypassed most of the optional exercises that were outlined in the posts, as she struggles to complete anything that does not have a deadline or accountability attached to it. Mary also said she got behind with the reading and had to binge to catch up.

Perhaps, I should have requested a daily response to the reading - or encouraged a defined reading strategy? The participants in Wright et al.'s (2010) study mentioned different personal reading strategies, such as reading and rereading, reading aloud or silently, line by line reflection, and a conscious choice about when the reflection occurs - either during the reading or after some time has passed. This may have helped the collaborators have a more concentrated experience - though, there is a fine line between too much direction and not enough. Learners do have to approach the content of their own will, if they are to have a transformative learning experience (King, 2009; Wright et al., 2010) and, yes, this study was voluntary, but we can never be sure whether they were always reading because they wanted to read or because they were participating in a study (Harris \& White, 2013; Nelson \& Hayes, 1981). The hope was that they would have a transformative experience, of course, but there 51 
was, inevitably, going to be an element of chore about the whole thing-and more expectations would have equalled even more chore, more study-like. I wanted the process to be as minimally invasive as possible, as they were not to know what they were getting themselves into, nor what life was going to throw at them during the three-week projectthree weeks can equally feel like an eternity or no time at all.

The length and accessibility of this project, as the brief interventions mentioned earlier (Cavanagh et al., 2013; Kemper, 2017), can be said to have shown positive signs, but the long-term sustainability of the collaborators' mindfulness habits are, as yet, unknown. Much like mindfulness, itself, perhaps we are focused on the present moment and not much bothered by the future? Or, rather more to the point, I think we need to recognise the ongoing practice aspect of mindful living. The collaborators do not say anything specifically about the length of our project, so we need to make some careful considerations, based on their experiences. Mary says that she has read information that she now cannot ignore-so, regardless of its length, it sounds like the words reached their intended audience? Rebecca needed the daily support and reminders to lift her positivity and resilience. Cordelia, also, mentioned an occasional respite from self-criticism - a start. Alana hopes her changes will be sustainable- hopes, not believes or trusts or knows. These experiences would all suggest a longer programme might be needed to make a dent in deep-rooted, negative beliefs - the medium of reading is effective, but accessibility is key. Online material gets the accessibility tick of approval - ongoing online material is the next, vital step, along with longitudinal research (Cavanagh et al., 2013).

\section{Reading experience and transformative learning}

And, now, we come to the heart of the whole story - is reading about mindfulness a natural transformative learning experience? Could this be a formula to effectively reach the many with the beautiful benefits of mindful living? Here, we break down the collaborators' stories and investigate whether their experiences fit into Mezirow's (1990) transformative learning process.

\section{i. $\quad$ Perspective}

The perspectives to note here are the understandings of mindfulness - the foundation of knowledge the collaborators entered the journey from and with. There was past 
experience of silent retreats for Mary, an introductory mindfulness course for Rebecca, Gestalt therapy for Alana, and mindful breathing exercises for Cordelia. The common explanation of mindfulness was that it was focusing on the present moment. This included focusing on their inner being and noticing their surroundings - their reactions to it, and interactions with it. They said mindfulness was an understanding of thoughts and the power they have over us-particularly stresses and worries. It was trying to wrest that power back. They entered this experience knowing the importance of mindfulness and wanting to have a reinforcing learning experience. As we heard from King (2009), transformation can only occur when we have the motivation to learn, the intention to change.

\section{ii. Experience}

The collaborators' experiences of reading for mindfulness brought up many colourful, contrasting words - challenging and mood changing. Surprising. Amusing. Annoying. Wow! Enjoyable, but a struggle. Poignant, silly, tricky, uplifting. Jarring and resonating. A scary thought! The act of reading, itself, provided a nice time to sit and just be-to focus on themselves. Mary, who feels guilty when she takes some time for herself, recognised that the reading and writing reflection was valuable self time - she still felt guilty about it, but it was a start to realise its worth. When her mind was buzzing, Rebecca felt that the reading helped to calm her down. The content involved questions that encouraged the next step of reflection-of understanding how they are living and what they want to change. And, perhaps most importantly—why.

\section{iii. Reflection}

Though critical reflection was prodded through the blog posts, the reflections, themselves, were deeply personal and based on previous experience-not necessarily mindfulness experience, but general life experience and circumstance. Due to her daily pain, Mary does not think that a foundation of gratitude is right for her-she prefers knowledge and understanding. This thought was reiterated by the other collaborators, in different ways - a recognition of what is possible for them, given their state of mind and life. Alana has experienced unimaginable hurt at the hands of others and, for her, gratitude, non-judgement, and changing her perspective on her 
relationships feel almost impossible — but she is willing to entertain the impossibility, to challenge it. In focusing on herself and how much her judgement of others affects her, she has discovered the bliss of letting go, allowing herself moments of quiet peace.

Reflection, for Rebecca, meant seeing herself mirrored in her children. Reading about worry and strategies to manage it, she realised that is exactly what she is working on with her son. She also reflected on how important community is to her, yet how much she lacks it - she feels she would benefit from more support. Cordelia reflected on putting her worries in perspective - and not just worries, but thoughts, in general. When it came to writing a 'Dear Me' letter, she said she felt silly doing it, but felt good afterwards. This was also a collective reflection-challenging the status quo. Challenging what they thought to be true of mindfulness. Challenging the way they are living their lives. Challenging the social norms - in slowing down and paying attention to ourselves, are we doing the "right" thing? Mary questions-filling our days is obligatory, is it not? Society says yes-mindfulness says golly no.

\section{iv. $\quad$ Meaning making}

While reflection is the looking back action, meaning making is part of the onward momentum. This was also a very individual experience and a lot of the meanings that were created resulted directly from their critical reflections. For Mary, pain is a constant in her life that she assigns meaning to and she knows that changing her perspective on pain, and how she experiences it, will be difficult. Though she is not comfortable feeling grateful for the pain she feels, she is using gratitude as a means to take back control. She receives a lot of negative feedback from consulting professionals and gratitude, she is discovering, is a way for her to take the positive back. Changing the perspectives with which we move forward is a common element of meaning making. Alana, also, found that the meaning she has been attributing to her daily worries is out of perspective, as she realised that she has managed everything that has come her way. Cordelia recognised that utilising others' experiences and skills as examples of her own potential and possibility is more useful than thinking of them as competition. 
Through this experience, the collaborators were establishing, or re-establishing, what is important to them. Rebecca realised that regular time spent riding horses, outside in nature, means a lot to her-allowing her time to clear her mind and focus on herself. She also acknowledged that, while it is great to know what is important to you, regular practice is necessary to keep training your focus on those things of meaning - and not get lost in the drudge. Through her reflection, Cordelia began to put her worries into perspective and discovered that, moving forward, having plans in place is a good way to put her mind at ease. These tools of a mindful mindgratitude, perspective, attention, focus-have been utilised by the collaborators to begin to use their time and their energy mindfully, instead of mindlessly. Meaningfully, instead of meaninglessly.

\section{v. Interpretation}

This final step looks at how the collaborators interpreted what they were reading and incorporated it into their daily living. A common thread through all the stories was a shift to focusing on the self-realising the value of less self-judgement, more selfcare. This focus covered several different aspects, including time, awareness, and mental perspective-we come full circle in this process. Rebecca recognised the importance of quiet time - utilising train travel as a time for focus, with no external demands. She is practicing choosing the goodness angle, over harsh, negative comparisons. Cordelia, though not yet succeeding at meditation, was going to keep trying to allow herself that peaceful meditation time. She said the magic words - find what works for me. Maybe, music will help? Alana has begun to de-clutter her mind, to take naps - to introduce practices that make her life more manageable. Spending time in nature, going out walking, and noticing their environments were mentioned by Rebecca, Cordelia, and Alana. Taking notice was also reiterated by Mary, with a greater awareness of her thoughts and her response to the world. She noted going forth with a questioning of - is it for me or just to keep someone else happy?

The journeys of the collaborators in this project seemingly, thankfully, promisingly appear to be progressive narratives (Gergen \& Gergen, 1983), following the transformative learning pathway (see Figure 5) and this is important to note, going forward, as a guide for anyone developing mindfulness teaching and learning content. Utilising the tools of 
personable content, a carefully constructed, connected programme, and guided critical reflection that follows Mezirow's (1990) process, can create a meaningful transformative learning experience for readers. They can be encouraged to assess the way they are living and start to make worthwhile adjustments-criticism to care. Guilt to goodness. Chaos to calm. While our experience may be different than that of traditional mindfulness practitioners, who practice meditation and breathing exercises on a regular basis, we arrive at the same place - a place of greater positive energy, self-care, understanding, and well-being, and less worry, mind clutter, and negative judgements. A place of living in the moment, mindfully. Mostly mindfully - it is a practice, after all.

Figure 5. Collaborators' mindfulness journey as a transformative learning experience

\begin{tabular}{|c|c|c|c|}
\hline $\begin{array}{l}\text { Mezirow's (1990) } \\
\text { stages } \\
\text { transformative } \\
\text { learning }\end{array}$ & $\begin{array}{l}\text { Machado and } \\
\text { Costa's (2015) steps } \\
\text { to mindfulness }\end{array}$ & The intersection & $\begin{array}{l}\text { Collaborators' } \\
\text { mindfulness journey }\end{array}$ \\
\hline Perspective & Introduction & $\begin{array}{l}\text { Our current life perspective } \\
\text { leads us to seek out } \\
\text { mindfulness. }\end{array}$ & $\begin{array}{l}\text { Past experience of } \\
\text { mindfulness and the life } \\
\text { circumstances they carry } \\
\text { with them. }\end{array}$ \\
\hline Experience & Brief practice & $\begin{array}{l}\text { Learning about and } \\
\text { practicing mindfulness is a } \\
\text { mental and physical } \\
\text { experience. }\end{array}$ & $\begin{array}{l}\text { Reading a blog about } \\
\text { mindfulness. }\end{array}$ \\
\hline Reflection & Awareness & $\begin{array}{l}\text { When we reflect on the } \\
\text { experience of mindfulness, } \\
\text { we develop a greater } \\
\text { awareness for life, as it is, } \\
\text { and how it could be. }\end{array}$ & $\begin{array}{l}\text { Looking back on past } \\
\text { understanding and how } \\
\text { they are living. }\end{array}$ \\
\hline Meaning-making & Deeper connection & $\begin{array}{l}\text { Attributing meaning in the } \\
\text { "right" places allows us to } \\
\text { create deeper connections } \\
\text { with our thoughts, actions, } \\
\text { and relationships. }\end{array}$ & $\begin{array}{l}\text { Making the internal shift } \\
\text { from how they are living to } \\
\text { how they want to live. }\end{array}$ \\
\hline Interpretation & Life engagement & $\begin{array}{l}\text { How we incorporate } \\
\text { mindfulness into our daily } \\
\text { life-turning living into } \\
\text { mindful living. }\end{array}$ & $\begin{array}{l}\text { The mindful practices they } \\
\text { intend to go forth with in } \\
\text { their daily living. }\end{array}$ \\
\hline
\end{tabular}




\section{Chapter Eight: Closing words}

\section{"Life is a dance. Mindfulness is witnessing that dance." Amit Ray}

What a journey this has been - and what a privilege to witness the stories of these four incredible women, who embraced the experience beyond my wildest imagination. Their words add a richness to the mindfulness experience - a vital reality check. I so want to believe that mindfulness practice can be the salve that soothes the hearts of all humanity, but this feedback has given me a good grounding. Hope, for sure. Motivation. But, mostly, fittingly_-perspective. I think we can take away that, no matter where we are in life, who we are in life, that we have the ability to change our minds, change our lives - all we need is to be open and willing (King, 2009). Mary, Rebecca, Cordelia, and Alana are all very different women, with diverse backgrounds, characteristics, and circumstances, but they all shared at least one thing in common - a feeling that there is more to life than how they have been experiencing it and the motivation to seek out change. Expressly-mindful change. While the quality of their experience, the qualia, was transformative, it remains to be seen if it is sustainable change.

The limitations that we have discovered are content style, structure, and durationthey each have their pros and cons. The relaxed style of blogs can equally elicit a deeply personal, emotional response or it can incite annoyance and a scepticism of the content. The reading of blogs, as with any social media platform, is also not particularly synonymous with discipline — rather, we are more likely to read sporadically, skim occasionally, scroll idly by the words on the page. What online content does have going for it, is its accessibility - 24/7, 365 days a year, forever. A solid, CBT-like structure, with worksheets, critical reflection, and guided instruction (Gunning, Richards, \& Prescott, 2011) can help to balance out the more casual aspects of the content, itself. From a research perspective, we need to see content and experience that spans a wider timeframe than three weeks-longitudinal studies that show both the immediate effects of reading about mindfulness and its ability to stimulate long-term transformation.

Further studies that investigate the connection between transformative learning and mindfulness would be welcome. The collaborators of this study did not know I was analysing their experiences from the perspective of transformative learning-would prior guidance on the stages of Mezirow's (1990) framework have any impact? Would a conscious 
awareness of the transformative learning process encourage the process to be followed through - consciously? Mindfully, even? The relationship between reading and mindfulness could also use more unpacking - the reading of other mindfulness material, from different sources, would be a beneficial research pathway. From my own perspective, I learned not from blogs, but from the publications of authors, such as Eckhart Tolle (1999, 2005), Elizabeth Gilbert (2006), Paulo Coelho (1993), Arianna Huffington (2015), Jeff Goins (2015), Russ Harris (2007) - I could go on and on. What is at odds to note is that there are numerous male writers of mindfulness content, yet male intrigue in mindfulness, their participation in mindfulness studies, pales in comparison to their female counterparts. Encouraging men to take part would be incredibly useful-a different perspective, yet again.

And, that is what we are all about-perspective. Experience. Reflection, meaning making, and interpretation (Mezirow, 1990) - all leading back, once more, to a fresh perspective. A wider perspective. A kinder perspective. This project has demonstrated that reading is a valid step on the journey to mindfulness - the words of wisdom behind the practice (Marx, 2015). We can see how becoming mindful (Machado \& Costa, 2015) is a natural transformative learning process-allowing us to recognise what is not working and create a deeper engagement with what is important. Being present. Right now. Taking notice. With care. As we move forward, if we can create mindfulness blog content that is affective, well structured, and widely accessible, we can turn an otherwise casual medium into a transformative learning platform that has the potential to change the stories of manyfor the better. 


\section{References}

"Everything that has a beginning has an ending. Make your peace with that and all will be well." Jack Kornfield

Adshead, G. (2013). The time of our lives: psychological disorders, time perception and the practice of mindfulness. European Journal of Psychotherapy and Counseling, 15(2), $139-150$.

Baer, R. A., Carmody, J., \& Hunsinger, M. (2012). Weekly change in mindfulness and perceived stress in a mindfulness-based stress reduction program. Journal of Clinical Psychology, 68(7), 755-765.

Beck, A. T. (1967). Depression: Clinical, experimental and theoretical aspects. New York, NY: Harper \& Row.

Bergomi, C., Tschacher, W., \& Kupper, Z. (2015). Meditation practice and self-reported mindfulness: a cross-sectional investigation of meditators and non-meditators using the comprehensive inventory of mindfulness experiences (CHIME). Mindfulness, 6(6), 1411-1421.

Berkovich-Ohana, A., Glicksohn, J., \& Goldstein, A. (2012). Mindfulness-induced changes in gamma band activity - implications for the default mode network, self-reference and attention. Clinical Neurophysiology, 123, 700-710.

Brookfield, S. (2003). Putting the critical back into critical pedagogy: A commentary on the path of dissent. Journal of Transformative Education, 1(2), 141-149.

Brown, B. (2018). Brené Brown. Retrieved from http://www.brenebrown.com.

Brown, K. W., \& Ryan, R. M. (2003). The benefits of being present: mindfulness and its role in psychological well-being. Journal of personality and social psychology, 84(4), 822.

Burke, C. A. (2010). Mindfulness-based approaches with children and adolescents: A preliminary review of current research in an emergent field. Journal of child and family studies, 19(2), 133-144.

Cavanagh, K., Strauss, C., Cicconi, F., Griffiths, N., Wyper, A., \& Jones, F. (2013). A randomised controlled trial of a brief online mindfulness-based intervention. Behaviour research and therapy, 51(9), 573-578.

Chapman, M. J., Hare, D. J., Caton, S., Donalds, D., McInnis, E., \& Mitchell, D. (2013). The use of mindfulness with people with intellectual disabilities: A systematic review and narrative analysis. Mindfulness, 4(2), 179-189.

Chopra, D., \& Kafatos, M. C. (2017). You are the universe: Discovering your cosmic self and why it matters. London, UK: Rider. 
Clandinin, D.J. (2013). Engaging in narrative inquiry. Walnut Creek, CA: Left Coast Press, Inc.

Clandinin, D. J., \& Connelly, F. M. (2000). Narrative inquiry: Experience and story in qualitative research. San Francisco, CA: Jossey-Bass.

Coatsworth, J. D., Duncan, L. G., Nix, R. L., Greenberg, M. T., Gayles, J. G., Bamberger, K. T., ... \& Demi, M. A. (2015). Integrating mindfulness with parent training: Effects of the mindfulness-enhanced strengthening families program. Developmental Psychology, $51(1), 26$.

Coelho, P. (1993). The alchemist. New York, NY: HarperCollins.

Creswell, J.W. (2003). Research design: Qualitative, quantitative, and mixed methods approaches $\left(2^{\text {nd }}\right.$ ed.). Thousand Oaks, CA: Sage.

Department of Health (2011). No health without mental health. Retrieved from https://www.gov.uk/government/uploads/system/uploads/attachment_data/file/213761/dh _124058.pdf.

Dewey, J. (1933). How we think. Chicago, IL: Regnery.

Dewey, J. (1938). Experience and education. New York, NY: Collier Books.

Fivush, R., Booker, J. A., \& Graci, M. E. (2017). Ongoing narrative meaning-making within events and across the life span. Imagination, Cognition and Personality, 37(2), 127-152.

Gergen, K. J., \& Gergen, M. M. (1983). Narratives of the self. In T. Sarbin, \& K. Scheibe (Eds.), Studies in social identity (pp. 254-273). New York, NY: Praeger.

Gergen, K. J., \& Gergen, M. M. (1988). Narrative and the self as relational. In L. Berkowitz (Ed.): Advances in Experimental Social Psychology (pp. 17-56). San Diego, CA: Academic Press.

Gilbert, E. (2006). Eat, pray, love. London, UK: Bloomsbury.

Goins, J. (2015). The art of work: A proven path to discovering what you were meant to do. Nashville, TN: Nelson Books.

Goldberg, S. B., Davis, J. M., \& Hoyt, W. T. (2013). The role of therapeutic alliance in mindfulness interventions: Therapeutic alliance in mindfulness training for smokers. Journal of clinical psychology, 69(9), 936-950.

Graci, M. E., \& Fivush, R. (2017). Narrative meaning making, attachment, and psychological growth and stress. Journal of Social and Personal Relationships, 34(4), 486-509.

Gunning, M., Richards, C., \& Prescott, N. (2011). Reading for wellbeing: a Healthy Reading scheme for children and young people aims to overcome barriers to mental health treatment. Community Practitioner, 84(4), 40-42. 
Hanley, A. W., Warner, A. R., Dehili, V. M., Canto, A. I., \& Garland, E. L. (2015). Washing dishes to wash the dishes: Brief instruction in an informal mindfulness practice. Mindfulness, 6(5), 1095-1103.

Harris, J., \& White, V. (2013). Hawthorne effect. In A dictionary of social work and social care (p. 78). Oxford, UK: Oxford University Press.

Harris, R. (2007). The happiness trap. London, UK: Robinson.

Hayes, S.C., Strosahl, K., \& Wilson, K.G. (1999). Acceptance and commitment therapy: An experiential approach to behaviour change. New York, NY: Guilford Press.

Heard, P. L., Hartman, S., \& Bushardt, S. C. (2013). Rekindling the flame: Using mindfulness to end nursing burnout. Nursing management, 44(11), 24-29.

Hodge, R. (2016). Adapting a MOOC for research: Lessons learned from the first presentation of literature and mental health: Reading for wellbeing. Journal of Interactive Media in Education, 2016(1).

Hoggan, C., \& Cranton, P. (2015). Promoting transformative learning through reading fiction. Journal of Transformative Education, 13(1), 6-25.

Huffington, A. (2015). Thrive: The third metric to redefining success and creating a life of well-being, wisdom, and wonder. London, UK: WH Allen.

Hülsheger, U. R., Alberts, H. J., Feinholdt, A., \& Lang, J. W. (2013). Benefits of mindfulness at work: the role of mindfulness in emotion regulation, emotional exhaustion, and job satisfaction. Journal of Applied Psychology, 98(2), 310.

Inckle, K. (2010). Telling tales? Using ethnographic fictions to speak embodied 'truth'. Qualitative Research, 10(1), 27-47.

Ives-Deliperi, V. L., Howells, F., Stein, D. J., Meintjes, E. M., \& Horn, N. (2013). The effects of mindfulness-based cognitive therapy in patients with bipolar disorder: a controlled functional MRI investigation. Journal of affective disorders, 150(3), 1152-1157.

Kabat-Zinn, J. (1990). Full catastrophe living: Using the wisdom of your body and mind in everyday life. New York, NY: Delacorte.

Kabat-Zinn, J. (1994). Wherever you go, there you are: mindfulness meditation in everyday life. New York, NY: Hyperion.

Kabat-Zinn, J. (2003). Mindfulness-based interventions in context: Past, present, and future. Clinical Psychology: Science and Practice, 10(2), 144-156.

Kemper, K. J. (2017). Brief online mindfulness training: immediate impact. Journal of evidence-based complementary \& alternative medicine, 22(1), 75-80. 
Kennedy, W. B. (1990). Integrating personal and social ideologies. In J. Mezirow \& Associates (Eds.), Fostering critical reflection in adulthood: A guide to transformative and emancipatory learning (pp. 99-115). San Francisco, CA: Jossey-Bass.

Khoury, B., Sharma, M., Rush, S. E., \& Fournier, C. (2015). Mindfulness-based stress reduction for healthy individuals: a meta-analysis. Journal of psychosomatic research, 78(6), 519-528.

King, K. P. (2009). Handbook of the evolving research of transformative learning. Charlotte, NC: Information Age.

Kinsella, E. A. (2007). Educating socially-responsive practitioners: What can the literary arts offer health-professional education? In D. E. Clover \& J. Stalker (Eds.), The arts and social justice: Re-crafting adult education and community cultural leadership (pp. 3960). Leicester, UK: National Institute of Adult Education.

Kramer, R. S. S., Weger, U. W., \& Sharma, D. (2013). The effect of mindfulness meditation on time perception. Consciousness and Cognition, 22, 846-852.

Lakoff, G., \& Johnson, M. (1980). Metaphors we live by. Chicago, IL: University of Chicago Press.

Leroy, H., Anseel, F., Dimitrova, N. G., \& Sels, L. (2013). Mindfulness, authentic functioning, and work engagement: A growth modeling approach. Journal of Vocational Behavior, 82(3), 238-247.

Lincoln, Y. S., \& Guba, E. G. (1985). Naturalistic inquiry (Vol. 75). Beverly Hills, CA: Sage.

McCracken, L. M., \& Vowles, K. E. (2014). Acceptance and commitment therapy and mindfulness for chronic pain: model, process, and progress. American Psychologist, 69(2), 178.

McLaine, S. (2015). Reading for wellbeing: What is bibliotherapy? Incite, 36(3), 24.

Machado, S. M., \& Costa, M. E. (2015). Mindfulness practice outcomes explained through the discourse of experienced practitioners. Mindfulness, 6(6), 1437-1447.

Marx, R. (2015). Accessibility versus integrity in secular mindfulness: A Buddhist commentary. Mindfulness, 6(5), 1153-1160.

Mezirow, J. (1997). Transformative learning: Theory to practice. New directions for adult and continuing education, 1997(74), 5-12.

Mezirow, J. \& Associates. (1990). Fostering critical reflection in adulthood: A guide to transformative and emancipatory learning. San Francisco, CA: Jossey-Bass. 
Morledge, T. J., Allexandre, D., Fox, E., Fu, A. Z., Higashi, M. K., Kruzikas, D. T., ... \& Reese, P. R. (2013). Feasibility of an online mindfulness program for stress management - a randomized, controlled trial. Annals of behavioral medicine, 46(2), 137148.

Mun, C. J., Okun, M. A., \& Karoly, P. (2014). Trait mindfulness and catastrophizing as mediators of the association between pain severity and pain-related impairment. Personality and Individual Differences, 66, 68-73.

Murphy, C., \& MacKillop, J. (2012). Living in the here and now: interrelationships between impulsivity, mindfulness, and alcohol misuse. Psychopharmacology, 219(2), 527-536.

Nelson, R. O., \& Hayes, S. C. (1981). Theoretical explanations for reactivity in selfmonitoring. Behavior Modification, 5(1), 3-14.

Noddings, N. (2003). Caring: A feminine approach to ethics and moral education ( $2^{\text {nd }}$ ed.). Oakland, CA: University of California Press.

Nussbaum, M. C. (1997). Cultivating humanity: A classical defense of reform in liberal education. Cambridge, MA: Harvard University Press.

Polusny, M. A., Erbes, C. R., Thuras, P., Moran, A., Lamberty, G. J., Collins, R. C., ... \& Lim, K. O. (2015). Mindfulness-based stress reduction for posttraumatic stress disorder among veterans: a randomized clinical trial. Jama, 314(5), 456-465.

Richardson, L. (2000). Writing: A method of inquiry. In N. Denzin, \& Y. Lincoln (Eds.), The handbook of qualitative research (2nd edition) (pp. 923-948). Thousand Oaks, CA: Sage.

Riessman, C. K. (1993). Narrative analysis (Vol. 30). Newbury Park, CA: Sage.

Sanko, J., Mckay, M., \& Rogers, S. (2016). Exploring the impact of mindfulness meditation training in pre-licensure and post graduate nurses. Nurse education today, 45, 142-147.

Segal, Z. V., Williams, J. M. G., \& Teasdale, J. D. (2001). Mindfulness-based cognitive therapy for depression. New York, NY: Guilford Press.

Sibinga, E. M., Perry-Parrish, C., Chung, S. E., Johnson, S. B., Smith, M., \& Ellen, J. M. (2013). School-based mindfulness instruction for urban male youth: A small randomized controlled trial. Preventive medicine, 57(6), 799-801.

Sibinga, E. M., Webb, L., Ghazarian, S. R., \& Ellen, J. M. (2016). School-based mindfulness instruction: an RCT. Pediatrics, 137(1), e20152532.

Silverman, D. (2000). Analyzing talk and text. In N. K. Denzin \& Y. S. Lincoln (Eds.), Handbook of qualitative research $\left(2^{\text {nd }}\right.$ ed., pp. 821-834). Thousand Oaks, CA: Sage.

Sinek, S. (2011). Start with why: How great leaders inspire everyone to take action. Penguin.

Sng, A. A., \& Janca, A. (2016). Mindfulness for personality disorders. Current opinion in psychiatry, 29(1), 70-76. 
Spijkerman, M. P. J., Pots, W. T. M., \& Bohlmeijer, E. T. (2016). Effectiveness of online mindfulness-based interventions in improving mental health: A review and meta-analysis of randomised controlled trials. Clinical psychology review, 45, 102-114.

Stelter, R. (2009). Experiencing mindfulness meditation-A client narrative perspective. International journal of qualitative studies on health and well-being, 4(3), 145-158.

Stephenson, K. R., Simpson, T. L., Martinez, M. E., \& Kearney, D. J. (2017). Changes in mindfulness and posttraumatic stress disorder symptoms among veterans enrolled in mindfulness-based stress reduction. Journal of clinical psychology, 73(3), 201-217.

Strauss, A. L., \& Corbin, J. (1990). Basics of qualitative research: Grounded theory procedures and techniques. Newbury Park, CA: Sage.

Tan, L. B., \& Martin, G. (2016). Mind full or mindful: A report on mindfulness and psychological health in healthy adolescents. International Journal of Adolescence and Youth, 21(1), 64-74.

Taylor, E. W., \& Cranton, P. (2012). The handbook of transformative learning: Theory, research, and practice. John Wiley \& Sons.

Taylor, N. Z., \& Millear, P. M. R. (2016). The contribution of mindfulness to predicting burnout in the workplace. Personality and Individual Differences, 89, 123-128.

Tolle, E. (1999). The power of now. London, UK: Hodder \& Stoughton.

Tolle, E. (2005). A new earth: Create a better life. London, UK: Penguin.

Wang, Q., Law, H. C., Li, Y., Xu, Z., \& Pang, W. (2017). Awareness and awakening: A narrative-oriented inquiry of undergraduate students' development of mindful agency in China. Frontiers in psychology, 8, 2036.

Witkiewitz, K., Bowen, S., Douglas, H., \& Hsu, S. H. (2013). Mindfulness-based relapse prevention for substance craving. Addictive behaviors, 38(2), 1563-1571.

Wright, R. R., Coryell, J. E., Martinez, M., Harmon, J., Henkin, R., \& Keehn, S. (2010). Rhyme, response, and reflection: An investigation of the possibilities for critical transformative learning through adult poetry reading. Journal of Transformative Education, 8(2), 103-123.

Wupperman, P., Fickling, M., Klemanski, D. H., Berking, M., \& Whitman, J. B. (2013). Borderline personality features and harmful dysregulated behavior: the mediational effect of mindfulness. Journal of clinical psychology, 69(9), 903-911. 


\section{Appendices}

Appendix 1 Blog post sample

\section{mindful over matters}

Hey there! Before we get into the nitty gritty, we need to know what we mean by mindfulness.

\begin{tabular}{|c|c|c|c|c|c|c|}
\hline SUN & MON & TUE & WED & THU & FRI & SAT \\
\hline $\begin{array}{c}15 \text { OCT } \\
\text { Intro } \\
\text { Background }\end{array}$ & $\begin{array}{c}16 \text { OCT } \\
\text { Intro } \\
\text { Mindfulness }\end{array}$ & $\begin{array}{c}17 \text { OCT } \\
\text { Intro } \\
\text { Gratitude }\end{array}$ & $\begin{array}{l}18 \mathrm{OCT} \\
\text { Rest day }\end{array}$ & $\begin{array}{c}19 \text { OCT } \\
\text { Awareness } \\
\text { Pace }\end{array}$ & $\begin{array}{c}20 \text { OCT } \\
\text { Awareness } \\
\text { Worry }\end{array}$ & $\begin{array}{c}21 \text { OCT } \\
\text { Awareness } \\
\text { Quiet focus }\end{array}$ \\
\hline $\begin{array}{l}22 \mathrm{OCT} \\
\text { Rest day }\end{array}$ & $\begin{array}{c}23 \text { OCT } \\
\text { Non- } \\
\text { judgement } \\
\text { Kindness }\end{array}$ & $\begin{array}{c}24 \text { OCT } \\
\text { Non- } \\
\text { judgement } \\
\text { Simplicity }\end{array}$ & $\begin{array}{c}25 \text { OCT } \\
\text { Non- } \\
\text { judgement } \\
\text { Choices }\end{array}$ & $\begin{array}{l}26 \text { OCT } \\
\text { Rest day }\end{array}$ & $\begin{array}{c}27 \text { OCT } \\
\text { Attention } \\
\text { Intention }\end{array}$ & $\begin{array}{c}28 \text { OCT } \\
\text { Attention } \\
\text { Engagement }\end{array}$ \\
\hline $\begin{array}{l}29 \text { OCT } \\
\text { Attention } \\
\text { Care }\end{array}$ & $\begin{array}{l}30 \mathrm{OCT} \\
\text { Rest day }\end{array}$ & $\begin{array}{c}31 \text { OCT } \\
\text { Unity } \\
\text { Connection }\end{array}$ & $\begin{array}{l}1 \text { NOV } \\
\text { Unity } \\
\text { Value }\end{array}$ & $\begin{array}{c}2 \text { NOV } \\
\text { Unity } \\
\text { Action }\end{array}$ & $\begin{array}{l}3 \text { NOV } \\
\text { Rest day }\end{array}$ & $\begin{array}{c}4 \text { NOV } \\
\text { Onward } \\
\text { journey }\end{array}$ \\
\hline
\end{tabular}

Some of you will come with previous experience and some will be complete beginners. Let's define what our mindfulness looks like.

We'll start with-

\section{what it's not}

Our mindfulness is not hocus pocus, airy fairy-ness. It's not about spending hours meditating or floating off to la la land. No disrespect to meditation or la la land - they definitely have their place, it's just not here.

Our mindfulness is not about changing our lives and becoming commune-living gypsies or spiritual gurus. Again, no disrespect. But, I think there can be a misconception that mindfulness is a bit hippy-dippy, softly-spoken, I can't think of a better term than airy fairy, so I'll use it again!

Our mindfulness isn't religious. And you'll find that, on the whole, most mindfulness-based practices aren't religious. Meditation and mindfulness may have their origins in Eastern religions, like Buddhism, but religious thought or practice play no part here.

Our mindfulness is not about shutting off our thoughts - in fact, no mindfulness is about shutting off thoughts, nor controlling them. It's about separating from them, realising that we're not our thoughts - it's about observing and understanding them. It's about being able to say thank you, mind, but that's enough now. 
Our mindfulness isn't about zoning out - it's about honing in. It's not about taking time out of our busy lives, it's about engaging in them. And by consciously choosing what we engage in, how and why, we might just find that busy isn't our go-to description of our days anymore.

\section{make our meaning}

We're using the definition of Jon Kabat-Zinn, who says mindfulness is being present, without judgement, and paying attention.

There's a bit of a fuzzy line between being present and paying attention, but we'll suss the differences as we talk more about them.

So, what does this mean for us?

In a nutshell, it means-

Trying not to think so much of the past or future and live now, fully awake (but sleeping well!) and making conscious choices.

It means trying to always be kind to ourselves and others - both in our heads and out loud. Trying not to judge books by their covers or react impulsively.

It means trying to live simply, with values at our core, and just making the most of our time.

You'll notice there's a common theme here-

Trying.

Mindfulness isn't a magic switch and it's not a constant energy.

It's a practice.

\section{how to be}

It is a practice, it takes energy — which sounds contradictory, shouldn't mindfulness be effortlessly light and easy-breezy? Airy fairy, even?!

Some of these buzz phrases (live now, be conscious) sound airy fairy, which I promised our mindfulness was not-and it isn't!

Our mindfulness is all about energy and how we choose to use it. It takes energy, but it also gives it back. Just like exercise-takes energy (sometimes energy we don't think we have to give!), but that run (ick!) or jog (meh) or walk (yeah!) energises us, in return.

Side note—no disrespect to runners. I don't run. You're amazing! 
Mindfulness isn't about changing our lives, it's about changing our minds. A shift in perspective and how we react to the things that happen to us.

Oh, we'll have many, many slip ups along the way. That's all a part of the journey. But, in keeping with the theme of non-judgement, we don't beat ourselves up-we just let those slip ups be, learn from them (probably make them again!) and move on.

As with any practice, the more we do it, the better we get, and the more natural and instinctive our actions become.

I know this stuff all sounds sweet and nice, but you might be thinking - that all sounds sweet and nice, but how do we actually do it? We'll break it all down when we talk about each specific element in more detail.

As Rachel Hunter used to say in those old Pantene ads-

It won't happen overnight, but it will happen.

\section{muse views}

In your background narratives, you talked a bit about your understanding of mindfulness. Today, just have a quick think about whether that was different to what we've talked about here? Is there anything in this post that you were (or weren't) expecting, or that you disagree with?

Tomorrow, we'll chat a bit about gratitude — which is part of mindfulness, but I couldn't work out where to put it, so it's here.

Front and centre.

The root of joy is gratefulness.

$\sim$ David Steindl-Rast

Enjoy your day.

$\mathrm{xx}$ 


\section{slow it down}

Hey there! Hope you had a refreshing day yesterday.

In our definition of mindfulness, the first element is present moment awareness-which is exactly as it sounds. Being here now.

Over the next three days (or nows!), we'll talk about pace, worry, and focus.

\begin{tabular}{|c|c|c|c|c|c|c|}
\hline SUN & MON & TUE & WED & THU & FRI & SAT \\
\hline $\begin{array}{c}15 \text { OCT } \\
\text { Intro } \\
\text { Background }\end{array}$ & $\begin{array}{c}16 \text { OCT } \\
\text { Intro } \\
\text { Mindfulness }\end{array}$ & $\begin{array}{c}17 \text { OCT } \\
\text { Intro } \\
\text { Gratitude }\end{array}$ & $\begin{array}{l}18 \text { OCT } \\
\text { Rest day }\end{array}$ & $\begin{array}{c}19 \text { OCT } \\
\text { Awareness } \\
\text { Pace }\end{array}$ & $\begin{array}{c}20 \text { OCT } \\
\text { Awareness } \\
\text { Worry }\end{array}$ & $\begin{array}{c}21 \text { OCT } \\
\text { Awareness } \\
\text { Quiet focus }\end{array}$ \\
\hline $\begin{array}{l}22 \mathrm{OCT} \\
\text { Rest day }\end{array}$ & $\begin{array}{c}23 \text { OCT } \\
\text { Non- } \\
\text { judgement } \\
\text { Kindness }\end{array}$ & $\begin{array}{c}24 \text { OCT } \\
\text { Non- } \\
\text { judgement } \\
\text { Simplicity }\end{array}$ & $\begin{array}{c}25 \text { OCT } \\
\text { Non- } \\
\text { judgement } \\
\text { Choices }\end{array}$ & $\begin{array}{l}26 \text { OCT } \\
\text { Rest day }\end{array}$ & $\begin{array}{c}27 \text { OCT } \\
\text { Attention } \\
\text { Intention }\end{array}$ & $\begin{array}{c}28 \text { OCT } \\
\text { Attention } \\
\text { Engagement }\end{array}$ \\
\hline $\begin{array}{c}29 \text { OCT } \\
\text { Attention } \\
\text { Care }\end{array}$ & $\begin{array}{l}30 \text { OCT } \\
\text { Rest day }\end{array}$ & $\begin{array}{c}31 \text { OCT } \\
\text { Unity } \\
\text { Connection }\end{array}$ & $\begin{array}{c}1 \mathrm{NOV} \\
\text { Unity } \\
\text { Value }\end{array}$ & $\begin{array}{c}2 \text { NOV } \\
\text { Unity } \\
\text { Action }\end{array}$ & $\begin{array}{l}3 \text { NOV } \\
\text { Rest day }\end{array}$ & $\begin{array}{l}4 \text { NOV } \\
\text { Onward } \\
\text { journey }\end{array}$ \\
\hline
\end{tabular}

We live a mile a moment, don't we? We're always on the go.

Always something to rush to-somewhere else to be.

The first puzzle piece of present moment awareness is slowing the heck down.

Slow doesn't mean boring. Or lazy.

Slow doesn't [always!] mean late.

It means present.

Present enough to actually experience our experience.

\section{why slow down}

Oh, golly, where do we start?!

It's that old catch 22-we mourn birthdays and how fast the time flies, yet we will it on, wishing the weeks away. Moanday, Tuesday blues, Humpday, Friday eve, Friyay! Saturday! Soon-to-be-Moanday, Moanday ...

Part of slowing down is trying to remove ourselves from what Eckhart Tolle calls psychological time. For the purposes of scheduling life, knowing where we want to be and 
when (note want, not need), it's good to recognise time. Clock time. It's one of the semiuseful things humans have created!

We'll talk more about that tomorrow.

But, when we start to base our moods and thoughts and rushed actions on a day (Moanday) or a time of day (moaning?!)—we're just losing a helluvalotta precious life hours.

So, slowing down means more life—-because we're not just living for the weekend.

Slowing down means longer life - it stands to reason that, when we're not stressed and rushing about everywhere, our minds and bodies can last longer.

Slowing down means better life-it means we're actually engaged in the journey, not just the A to $\mathrm{P}$ or $\mathrm{K}$ to $\mathrm{V}$.

We must not allow the clock or calendar to blind us to the fact that each moment of life is a miracle and mystery.

$\sim$ H.G. Wells

Even Moandays-miracles and mysteries!

\section{take a breath}

The easiest way to slow down is to stop and breathe. How often do we completely shut off and focus on our breath?

Sleeping doesn't count!

I mean stop in the middle of our day, in the middle of a meal, in the middle of a meltdown?

It doesn't have to be a massive, obvious breath, but just conscious. Turn inward.

Breathing is one of those things central to living, it just happens, and when we hone in on it, we can't help but slow down and experience the present moment.

In each breath, that's all there is. Just that moment.

And, oh my, the precious release - in the mind, the body, and the soul.

Because, when we're rushing, we're not breathing-we're panting.

When we're rushing, we're not thinking —we're stressing.

When we rush, we don't experience_-life passes by in a haze of busy, stressy panting! 
Side note-give this a go at some stage today. Just stop. Right now? Find a comfy seat. Hopefully, you're already there! Close your eyes (after you read this!) and breathe. Even if only for 30 seconds. If you've got any aches and pains, try and consciously send your breath to those places. Feel the cool inhalation, the rise of your body, and the warm, delicious exhalation, the letting go. Do you feel any of the pain melt away?

Side side note-Even though some of our brains (mine's one of them!) don't have the foggiest idea about science, our bodies still know how to breathe in oxygen and breathe out carbon dioxide. How clever is that? Miracle and mystery!

\section{chill out time}

Once she stopped rushing through life, she was amazed how much more life she had time for.

$\sim$ Unknown

Right?

How many of you have been reading this post and thinking yeah, well, this is all fine and dandy, but it's just not practical? Life is busy and it's fast and there's nothing we can do about that, we've got to run to keep up?

How many of you are made to feel guilty for taking a breather? Not necessarily by someone else - more than likely, you beat yourself up for having a break and spend the time listing all the things you should be doing, instead?

Yes, life is busy. Yes, I swear it gets faster by the minute. But, I think-this won't apply to everyone, but think what it means to you-we can take on too much.

We can take on too much and it's not always of value to us.

We're going to talk more about values and defining what's important in our not-too-distant nows.

\section{muse views}

Is there anything in your life that you just think "why am I doing this?" And, when you think of that why, really think-

Am I questioning this because it truly doesn't have any value or am I questioning this because of my current perspective on its value? Our current perspectives are shaped by any number of things - our energy levels, our moods, our feelings toward the people, the tasks, the situations we're surrounded by.

Try to remove any personal biases, just for the minute, and think - these things that I'm doing, that are filling my days and making them busy, which are really important?

Which ones could just lighten my load? 
And, think about how much time you take for yourself?

You know the old airline safety instructions-fit your own oxygen mask before you help someone else?

Oprah says we need to be full of ourselves. Not in the way that society views that statement - full of ego. But, we need to fill ourselves up to be of best service to others.

And, just like when our car needs petrol —we need to stop to fill 'er up!

Slow down.

Stop.

Breathe.

What's one thing you can do to enjoy your day?

Do it!

$\mathrm{XX}$ 


\section{pick your path}

Hey there!

I won't dilly-dally today (not like yesterday!) — life is all about choices.

\begin{tabular}{|c|c|c|c|c|c|c|}
\hline SUN & MON & TUE & WED & THU & FRI & SAT \\
\hline $\begin{array}{c}15 \text { OCT } \\
\text { Intro } \\
\text { Background }\end{array}$ & $\begin{array}{c}16 \text { OCT } \\
\text { Intro } \\
\text { Mindfulness }\end{array}$ & $\begin{array}{c}17 \text { OCT } \\
\text { Intro } \\
\text { Gratitude }\end{array}$ & $\begin{array}{l}18 \text { OCT } \\
\text { Rest day }\end{array}$ & $\begin{array}{c}19 \text { OCT } \\
\text { Awareness } \\
\text { Pace }\end{array}$ & $\begin{array}{c}20 \text { OCT } \\
\text { Awareness } \\
\text { Worry }\end{array}$ & $\begin{array}{c}21 \text { OCT } \\
\text { Awareness } \\
\text { Quiet focus }\end{array}$ \\
\hline $\begin{array}{l}22 \mathrm{OCT} \\
\text { Rest day }\end{array}$ & $\begin{array}{c}23 \text { OCT } \\
\text { Non- } \\
\text { judgement } \\
\text { Kindness }\end{array}$ & $\begin{array}{c}24 \text { OCT } \\
\text { Non- } \\
\text { judgement } \\
\text { Simplicity }\end{array}$ & $\begin{array}{c}25 \text { OCT } \\
\text { Non- } \\
\text { judgement } \\
\text { Choices }\end{array}$ & $\begin{array}{l}26 \text { OCT } \\
\text { Rest day }\end{array}$ & $\begin{array}{c}27 \text { OCT } \\
\text { Attention } \\
\text { Intention }\end{array}$ & $\begin{array}{c}28 \mathrm{OCT} \\
\text { Attention } \\
\text { Engagement }\end{array}$ \\
\hline $\begin{array}{l}29 \text { OCT } \\
\text { Attention } \\
\text { Care }\end{array}$ & $\begin{array}{l}30 \text { OCT } \\
\text { Rest day }\end{array}$ & $\begin{array}{c}31 \text { OCT } \\
\text { Unity } \\
\text { Connection }\end{array}$ & $\begin{array}{c}1 \mathrm{NOV} \\
\text { Unity } \\
\text { Value }\end{array}$ & $\begin{array}{c}2 \text { NOV } \\
\text { Unity } \\
\text { Action }\end{array}$ & $\begin{array}{l}3 \mathrm{NOV} \\
\text { Rest day }\end{array}$ & $\begin{array}{c}4 \text { NOV } \\
\text { Onward } \\
\text { journey }\end{array}$ \\
\hline
\end{tabular}

\section{free your mind}

Do you know what really grinds my gears? And, this is so ridiculous-

Hanging the washing out.

I know, right?!

We've got a rotary clothes line and when it's windy (hello, Wellington!), it moves every bloody time I go to hang something up.

So. Frustrating!

\section{So ridiculous.}

But, on the weekend, as I was about to grumble headlong into the wind-

I just stopped.

Took a breath and smiled.

I chose to list all the things I was grateful for-how the wind magically spins the washing line to dry the clothes, and the electricity to run the washing machine, and even having a washing machine, for the water and detergent to fill it, actually having clothes to wash ...

And, then I saw a beautiful Tui-for only the second time since I actually knew what they looked like (that's another story!). And my neighbour started cranking some old school tunes and I had a little boogie, dancing with the wind and the birds and the washing line. 
It sounds a bit (completely!) cuckoo, but it sure was a helluva lot nicer than feeling frustrated and grumpy.

\section{muse views}

Play a game with me-

Think of something right now that makes you frustrated or angry.

Feel that frustration or that anger.

Really feel it. Is your heart beating faster? Your blood rushing, your muscles tense, your jaw clenched?

Now, keep thinking of that same thing, but change your feeling to acceptance.

Take a deep, refreshing breath and let go. Just let it be.

Next, move from acceptance to gratitude.

That might be a challenge, but keep that thought or experience (or person?!) in your mind and feel grateful for it or them.

You might even say a quiet "thank you."

After you've felt grateful, shift into wonder. Let yourself just be genuinely surprised-in a good way.

Wow.

And, once you've felt that wonder, that awe, change your mind again —-this time into joy.

Smile and let that thought, experience, or person go. Move on.

Now, let's take stock.

What felt good? The tense frustration or anger?

Or was the calming acceptance, gratitude, the wonder or wonderful joy a more pleasant experience?

If we can, just in this short game, choose what we feel about something or someone-why would we ever choose the negative?

\section{leaving the past}

I am not what happened to me. I am what I choose to become. 
$\sim$ Carl Jung, Swiss psychiatrist

This.

This is why. In dark situations, choosing may not even feel like an option.

When heartbreaking things happen, choosing the light is deep, deep in the easier-said-thandone basket—right alongside gratitude and non-judgement.

Why be thankful for heartbreak?

How do we not judge those who do us wrong?

How can we just go on?

Put simply - not lightly, this isn't about downplaying anyone's experiences, but for the purposes of this post, we're going to look at this in black and white.

Even though real life is anything but.

If we look at things simply—we have to go on, right?

This is life - this is it. No turning back, only moving forward.

As we talked about in the gratitude post, we can find even the most basic of things to be thankful for-a refreshing breath, a cloudless sky, a hot cuppa.

And judgement? Well, no matter how much we may judge others, the only person we're really harming is ourselves.

Sadness, bitterness, ill will — as much as we may want to wish it on our enemies, they get to choose how they react to it (and they're far more likely to react to their own thoughts than to our words or actions).

And that's if we even display our animosity outwardly to them.

If we're just seething quietly away to ourselves, well—we're just seething quietly away to ourselves.

Either way, we don't win.

Unless, we choose to change our tune.

\section{a new view}

Whether we believe it to be true or not, whether we believe ourselves capable of it -we have the choice as to how we react to things and people and situations. 
Just like the washing line example (lame, lame story, I know!), we can choose whether we want to get upset and dwell in the dark places, or say c'est la vie, learn a little lesson, do a wee jig, and move on.

It sounds like I'm making light here, but I guess that's really the point - that we will continue to live in the dark, until we choose to get up and open those curtains wide and let the light shine in.

And we shine on out.

This doesn't mean that we'll never come into harm or experience hurtful things-life happens (and it can be a bitch!). But, by choosing how we react? Sometimes, we can avoid the hurt altogether —or, at the very least, we take the power back from those trying to hurt us.

We can deal with it a bit better, move on a little quicker.

We would often say this person hurt us or that person made us mad — but that's only true if we let it be true.

It's not their doing-it's our choice.

Consciousness is responsibility_taking care of our own hearts and minds and wellbeing.

Consciousness opens our eyes - it gives us the awareness to be able to direct our energy and our life in the direction we want it to go.

Consciousness - the consciousness of becoming mindful is living with the light on (not literally, save power, save the planet!).

We don't see things as they are, we see them as we are.

Anaïs Nin

How do you want to see things?

Enjoy your day.

$\mathrm{xx}$ 


\section{what's your why}

Hey there! Hope you had a beautiful day off yesterday.

We've now travelled through awareness and non-judgement, and we've arrived at our next stop-

Attention.

Purposeful attention.

Over the next few days, we'll spend our time talking about our guiding intentions, what we're engaging with, and being sure to pay good attention to care-self care.

\begin{tabular}{|c|c|c|c|c|c|c|}
\hline SUN & MON & TUE & WED & THU & FRI & SAT \\
\hline $\begin{array}{c}15 \text { OCT } \\
\text { Intro } \\
\text { Background }\end{array}$ & $\begin{array}{c}16 \text { OCT } \\
\text { Intro } \\
\text { Mindfulness }\end{array}$ & $\begin{array}{c}17 \text { OCT } \\
\text { Intro } \\
\text { Gratitude }\end{array}$ & $\begin{array}{l}18 \mathrm{OCT} \\
\text { Rest day }\end{array}$ & $\begin{array}{c}19 \text { OCT } \\
\text { Awareness } \\
\text { Pace }\end{array}$ & $\begin{array}{c}20 \text { OCT } \\
\text { Awareness } \\
\text { Worry }\end{array}$ & $\begin{array}{c}21 \text { OCT } \\
\text { Awareness } \\
\text { Quiet focus }\end{array}$ \\
\hline $\begin{array}{l}22 \text { OCT } \\
\text { Rest day }\end{array}$ & $\begin{array}{c}23 \text { OCT } \\
\text { Non- } \\
\text { judgement } \\
\text { Kindness }\end{array}$ & $\begin{array}{c}24 \text { OCT } \\
\text { Non- } \\
\text { judgement } \\
\text { Simplicity }\end{array}$ & $\begin{array}{c}25 \text { ОСТ } \\
\text { Non- } \\
\text { judgement } \\
\text { Choices }\end{array}$ & $\begin{array}{l}26 \text { OCT } \\
\text { Rest day }\end{array}$ & $\begin{array}{c}27 \text { OCT } \\
\text { Attention } \\
\text { Intention }\end{array}$ & $\begin{array}{c}28 \text { OCT } \\
\text { Attention } \\
\text { Engagement }\end{array}$ \\
\hline $\begin{array}{l}29 \text { OCT } \\
\text { Attention } \\
\text { Care }\end{array}$ & $\begin{array}{l}30 \mathrm{OCT} \\
\text { Rest day }\end{array}$ & $\begin{array}{c}31 \text { OCT } \\
\text { Unity } \\
\text { Connection }\end{array}$ & $\begin{array}{l}1 \text { NOV } \\
\text { Unity } \\
\text { Value }\end{array}$ & $\begin{array}{l}2 \text { NOV } \\
\text { Unity } \\
\text { Action }\end{array}$ & $\begin{array}{l}3 \mathrm{NOV} \\
\text { Rest day }\end{array}$ & $\begin{array}{l}4 \text { NOV } \\
\text { Onward } \\
\text { journey }\end{array}$ \\
\hline
\end{tabular}

Let's get cracking!

\section{start our day}

Intentions are what should get us out of bed in the morning - not just out of bed, but be delighted to get out of bed. Ha!

Before a life change, a new experience, simply before we start each day, we should know what our intention/s is/are.

But, they're too often missing in action, skipped over in the hustle and bustle of life, and that's when things go a bit wayward and, all of a sudden, heyo! It's nearly Christmas and we think-where the hell has the year gone?!!

Live less out of habit and more out of intent.

$\sim$ Unknown

See? If there was more intent, we would know who said that quote! 
The definition of intention is a purpose. Intentional—done with purpose.

And mindfulness? Well, that's all about living with intent, with purpose.

We fall into the trap of routine, of living out of habit.

Habit: an acquired behaviour pattern regularly followed until it has become almost involuntary.

Autopilot.

We do things, we do life, without really thinking about it.

\section{defining what's important}

When we set our intentions, we're defining what's important to us.

How often do we actually ask ourselves that question?

When we're arguing over what to watch on the telly? Is this important to us?

When we're mindlessly scrolling through FB? Is this important?

When we're getting frustrated at the washing line? Important?!

We can think of setting intentions like this-

If we go to the supermarket and buy salt ' $n$ vinegar chippies, Kiwi onion dip, Whittaker's peanut butter chocolate, hokey pokey ice cream-it's our intention to eat that stuff, right?

Not that we really need to-we've likely bought it all without really thinking about it, without any intention. But, through that action, we're now going to eat a bunch of crap (delicious crap!) that's going to be really bad for us-delicious, but bad.

When our intention is lacking (or MIA), we make unhealthy, unimportant choices.

On the other hand, if we go to the supermarket with the intention that we're going to be good to ourselves (and our families), we'll buy lots of delicious fresh fruit and vegetables, natural yoghurt, rice crackers, hummus - and a little Whittaker's choc treat!

Intentions help us to make those mindful, conscious, healthy (not just food!) decisions.

And they don't have to be big, sweeping intentions - it's not about setting our grand purpose for life. It's simply saying-

Today, I will try my best.

Today, I'll be good to myself. 
Today, I'll be grateful. I'll be kind. I'll share my love.

Today, I will not sweat the small stuff. The spilt milk, bad hair day, the traffic jam. If it wouldn't matter on the day that I fall in love or give birth or during a natural disaster or health crisis? It doesn't matter. It's not important.

\section{the golden circle}

How do we help to define what's important?

Actually, it's not how, or what.

It's why.

\section{muse views}

What's your why? Or what are your whys?

Do they guide your whats and hows, or is it the other way around?

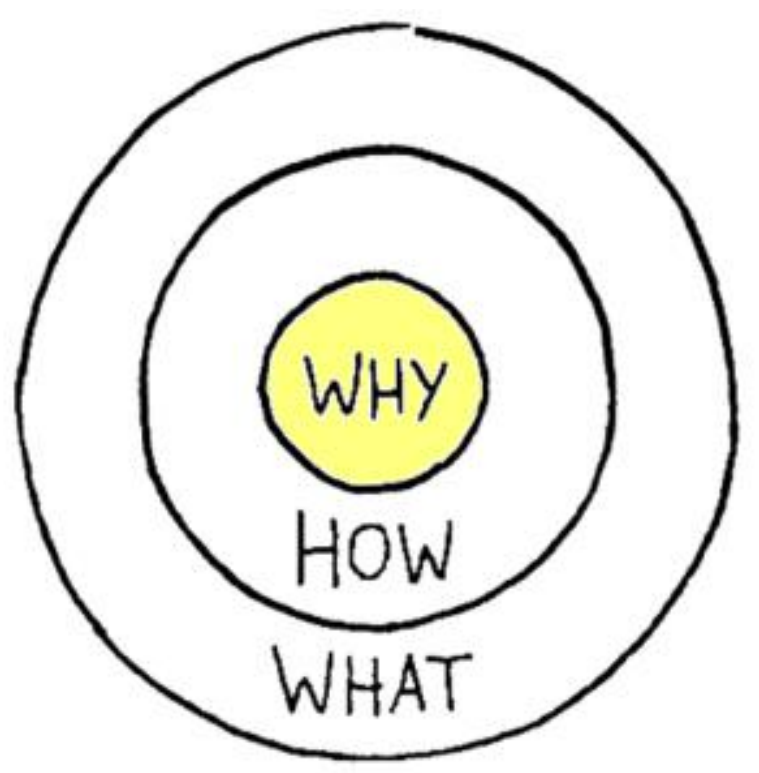

The habits (bad habits) that we get into? They're whats. But, what's important?

Why—and not for profit, but for purpose.

Why $=$ purpose. Purpose $=$ intention. We've come full circle — full golden circle!

If you want to hear more about the golden circle, watch Simon Sinek's genius TED talk.

If we start our days with intention, we start our days with why. 
What isn't enough to get us out of bed in the morning.

Going to work. What? Why?!

Because when we go to work, we impact lives. No matter what we do, we're having an effect on people. Earning a living is a happy byproduct, but it's not the driving force.

What are we doing? Going to the supermarket. Meh.

Why are we going to the supermarket? Because we're going to bake a cake and take it to Nana's house.

What? Going for a run. Ugh, why?

We want to breathe in nature and breathe out life - to be kind to this body, the only one we've got.

I'm no runner, but that sounds nice, right?!

Tomorrow, we're going to delve further into what we're engaging with in our daily lives.

And why.

Enjoy your day.

$\mathrm{XX}$ 


\section{manifest your life}

Hey there! How're you doing?

I named this post after manifestation — which is a bit of an airy fairy idea that we're going to ground in reality.

You may have heard of manifestation guides or plans or weekends? Essentially, it involves a lot of meditation and visualisations of your dream life, making vision boards, affirmation cards and the like.

I'm not knocking it. I've actually done a manifestation weekend (or my version of one, anyway!) and when you look past all the airy fairyness and get down to the nuts and boltsmanifesting your life is actually living the life that you want to live.

It doesn't happen in our heads—we make it happen.

It's the action we take.

\begin{tabular}{|c|c|c|c|c|c|c|}
\hline SUN & MON & TUE & WED & THU & FRI & SAT \\
\hline $\begin{array}{c}15 \text { OCT } \\
\text { Intro } \\
\text { Background }\end{array}$ & $\begin{array}{c}16 \text { OCT } \\
\text { Intro } \\
\text { Mindfulness }\end{array}$ & $\begin{array}{c}17 \text { OCT } \\
\text { Intro } \\
\text { Gratitude }\end{array}$ & $\begin{array}{l}18 \mathrm{OCT} \\
\text { Rest day }\end{array}$ & $\begin{array}{c}19 \text { OCT } \\
\text { Awareness } \\
\text { Pace }\end{array}$ & $\begin{array}{c}20 \text { OCT } \\
\text { Awareness } \\
\text { Worry }\end{array}$ & $\begin{array}{c}21 \text { OCT } \\
\text { Awareness } \\
\text { Quiet focus }\end{array}$ \\
\hline $\begin{array}{l}22 \text { OCT } \\
\text { Rest day }\end{array}$ & $\begin{array}{c}23 \text { OCT } \\
\text { Non- } \\
\text { judgement } \\
\text { Kindness }\end{array}$ & $\begin{array}{c}24 \text { OCT } \\
\text { Non- } \\
\text { judgement } \\
\text { Simplicity }\end{array}$ & $\begin{array}{c}25 \text { OCT } \\
\text { Non- } \\
\text { judgement } \\
\text { Choices }\end{array}$ & $\begin{array}{l}26 \text { OCT } \\
\text { Rest day }\end{array}$ & $\begin{array}{c}27 \text { OCT } \\
\text { Attention } \\
\text { Intention }\end{array}$ & $\begin{array}{c}28 \text { OCT } \\
\text { Attention } \\
\text { Engagement }\end{array}$ \\
\hline $\begin{array}{l}29 \text { OCT } \\
\text { Attention } \\
\text { Care }\end{array}$ & $\begin{array}{l}30 \text { OCT } \\
\text { Rest day }\end{array}$ & $\begin{array}{c}31 \text { OCT } \\
\text { Unity } \\
\text { Connection }\end{array}$ & $\begin{array}{l}1 \text { NOV } \\
\text { Unity } \\
\text { Value }\end{array}$ & $\begin{array}{c}2 \text { NOV } \\
\text { Unity } \\
\text { Action }\end{array}$ & $\begin{array}{l}3 \mathrm{NOV} \\
\text { Rest day }\end{array}$ & $\begin{array}{c}4 \text { NOV } \\
\text { Onward } \\
\text { journey }\end{array}$ \\
\hline
\end{tabular}

We have to break with tradition and have four sections today because I think there are four key steps to living a mindful life-simplicity, clarity, positivity, activity.

I'm stealing from an earlier post I wrote when I did my manifestation weekend-you're welcome to read it if you want a little extra background.

\section{clear the decks}

First step to mindful living? Simplicity.

We have so much clutter and distraction around us - calm and inner peace is a daily struggle when it should be calm and peaceful!

In order to live the life we want, we first have to find it (purposeful attention) and that means getting rid of all the unnecessary baggage that we carry with us - mental and material. 
This won't happen overnight, but it will happen (where have we heard that before?!) —it just takes a little time and energy. I've thrown out so much in the past few years-donated, recycled, forgotten, just generally binned. There's all this stuff we live with that we don't actually live with, use, need.

Or particularly want, for that matter!

All it's doing is weighing us down. And the mental freedom that comes from material freedom? Oh, the relief!

Simplicity—starting from a place of calm and inner peace.

\section{strength in clarity}

Step two-clarity. Knowing exactly what we want.

When it's not so hidden in all the kerfuffle, knowing what we want-our focus, our purpose, is easier to find.

It starts with knowing who we want to be.

A mindful healer? A mindful carer? A mindful entertainer, innovator, artist, teacher?

These aren't job titles - they're our why. They're the categories of beings that we want to spend our days, well, being!

When we're clear on our why (I'm a creative, I'm a leader, I'm a provider) — then we can start honing in on the specifics. On our whats and hows.

How can I be creative on a daily basis? What am I going to create?

If you don't know? That's okay, too. We all go through moments (months or years!) where we think what the hell am I doing? Why am I here?

And, our purposes can change — sometimes as often as we change our socks!

If you're not sure you've ever really had a purpose? That's more than okay, too. But, I'd say it's not because you don't have one (or many!) —you just haven't found it yet.

Or, sometimes, we're so caught up in the mess of life we don't recognise that what we're doing is actually what we're meant to be doing — we just need to see it in a different light.

So, what do you want to do today?

Start with simplicity and the clarity will be sure to follow. 


\section{a positive mindset}

Step three is positivity - poetry! We have to believe that we're worthy of living the life we want to live.

None of this negative, never gonna happen, not good enough bollocks that our minds feed us - none of that. We don't have time for that!

We're here for truth and if we're going to manifest the life we want-aka live the life we want, I'm going to assume here that we're all after a positive life experience and not a negative one?!

Mindfulness is key to a positive mindset.

When we leave past regrets and future worries where they lie? It's easier to be positive.

When we purposely choose what we're paying attention to and engaging with, it's easier to be positive.

I think the non-judgement slice of this mindful pizza would say that we shouldn't view anything as positive or negative, but I'm just not so sure that going through life with a neutral mindset is the way to go? Do you agree or disagree?

We're not saying we have to be upbeat, perky positive all day, every day-but erring on the side of a little positive energy, enthusiasm, motivation is good fuel for our actions.

And, we can't stress enough that you are worthy.

You're worthy of the life you want to live.

\section{it's action stations}

The final step? The action, baby!

If we want to start living a mindful life, it won't just happen-like clearing the decks, we've got to make it happen.

If you want something you've never had, you must be willing to do something you've never done.

$\sim$ Thomas Jefferson

Sounds a little scary, right?

It is, but when we lay the groundwork - the simple, clear, positive groundwork? The action isn't as scary as it seems. 
When I watch any gymnastics or freestyle skiing, I often think holyfreakin'moly, how did they ever do that for the first time?! Looks beyond scary-terrifying, even!

But, of course, they work their way there. They start small- they build strength, learn the basics, and practice, practice, practice. No doubt with a few bruises along the way. They always brush themselves off and try again. They take action.

We can think of our lives in the same way.

Well, not quite the same way - we're not talking about learning triple back somersaults or triple back somersaults with massive floppy skis hanging from our feet!

We're talking a mind change — not even a dramatic life change (unless you want it to!).

It starts small—with a choice.

A choice that says I'm not going to settle for less than I deserve.

A choice that says life is for the living and I'm here to live it, fully.

A choice to clear the decks and surround ourselves and our loved ones with what's important.

And, we don't have to do everything all at once! In fact, that might be the opposite of what we're trying to achieve?!

The choice is enough for the moment.

In the next moment, you might get a box and write 'to donate' on it.

Then, moment by moment, it will be filled to full.

But, it started small.

Enjoy your day.

$\mathrm{XX}$ 


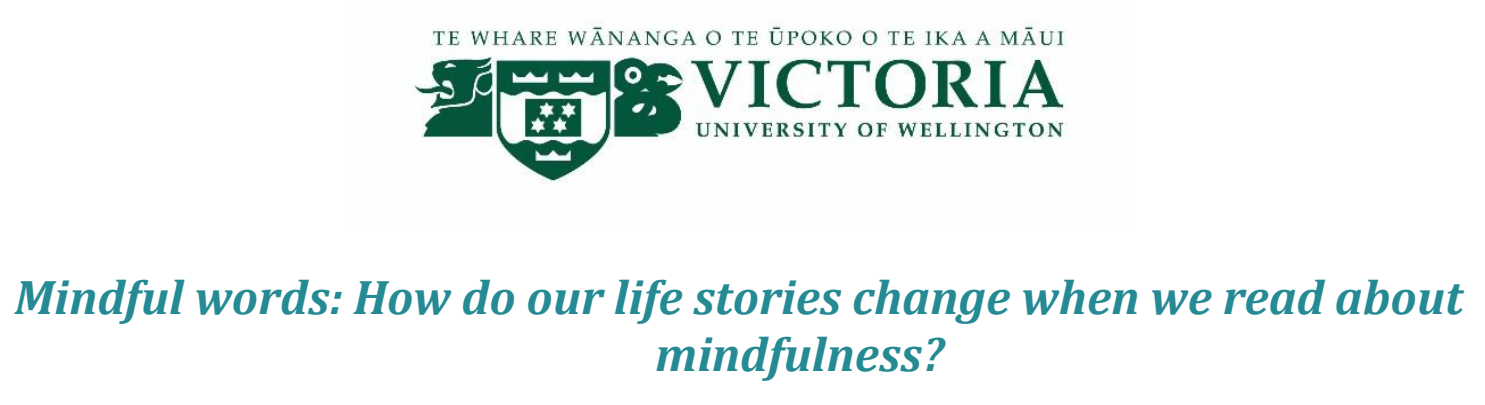

INFORMATION SHEET FOR PARTICIPANTS

Thank you so much for your interest in this project-l'm very grateful that you're here. Please read this information before confirming that you're willing to take part. If you decide to participate, welcome aboard! If you decide that it's not for you, I understand and respect your decision.

\section{Who am I?}

My name's Julia Watkin and I'm a Master of Education student at Victoria University of Wellington. This research project is work toward my thesis.

\section{What is the aim of the project?}

This research is about investigating the impact of reading for mindfulness. Mindfulness is defined here as paying attention, in the present moment, without judgement. Mindfulness is being shown to have positive effects on things like focus, mental wellbeing, and contentment, and is traditionally developed through meditation and breathing practices, but this research is interested in whether reading about mindfulness has any impact on your life-on your sense of wellbeing, your relationship with others, your engagement in daily life.

This research has been approved by the Victoria University of Wellington Human Ethics Committee, reference number 0000025082.

\section{How can you help?}

If you agree to take part, you'll sign a consent form and complete a pre-project reflection, which will include questions about who you are and your current life situation.

You'll read short blog posts about mindfulness on unitymuse.com from Sunday 15 October to Saturday 4 November, in the format of three days on, one day off, with focus on present moment awareness, non-judgement, and purposeful attention. You'll write a reflection journal to keep track of things that resonate with you and changes (if any) that may be resulting in your mind and in your life.

At the end of the project, you'll have a chat with me to discuss your experience. In the thesis, your reflections will be written up to illustrate the impact (if any) the mindfulness reading had on your life.

This will be a very open and honest process. You can ask me anything, at any time. You can refuse to answer any question, without giving a reason. You can withdraw from the study by contacting me 
at any time before 31 December 2017. If you withdraw, the information you provided will be returned to you or securely disposed of.

\section{What will happen to the information you give?}

This research is confidential-only the researcher and supervisor named below will be aware of your identity and you will not be identifiable in the final thesis. The only exception to the confidentiality clause is if you disclose anything that leads me to believe you may be experiencing distress, as a result of the project. In this case, we will call on Jude West, MNZAC, Registered Counsellor and Wellbeing Advisor, for support. Mindfulness has not been shown to have any negative consequences, so this is not expected, but it is important for you to know that support is in place for you.

Only my supervisor and I will read your journal reflections and post-project discussion notes. All written material and copies will be kept in locked storage and securely disposed of on 30 April 2019.

\section{What will the project produce?}

The information from my research will be used in my Master's thesis.

\section{If you accept this invitation, what are your rights as a research participant?}

Participation is completely your choice. If you decide to participate, you have the right to:

- $\quad$ choose not to answer any question;

- $\quad$ withdraw from the study before 31 December 2017;

- $\quad$ ask any questions about the study at any time;

- $\quad$ keep copies of your journal reflections;

- $\quad$ choose your own pseudonym to be used in the thesis;

- read over and comment on a written summary of your information;

- $\quad$ read any reports of this research by emailing the researcher.

If you have any questions or issues, who can you contact?

If you have any questions, now or in the future, please feel free to contact:

\section{Student researcher:}

Name: Julia Watkin

Email: julia.watkin@vuw.ac.nz

\section{Supervisor:}

Name: Dr Barrie Gordon

Email: barrie.gordon@vuw.ac.nz

Phone: $+64-4-463-9770$

\section{Human Ethics Committee information}

If you have any concerns about the ethical conduct of the research you may contact the Victoria University HEC Convenor: Associate Professor Susan Corbett. Email susan.corbett@vuw.ac.nz or telephone +64-4-4635480. 
Appendix 3 Consent form

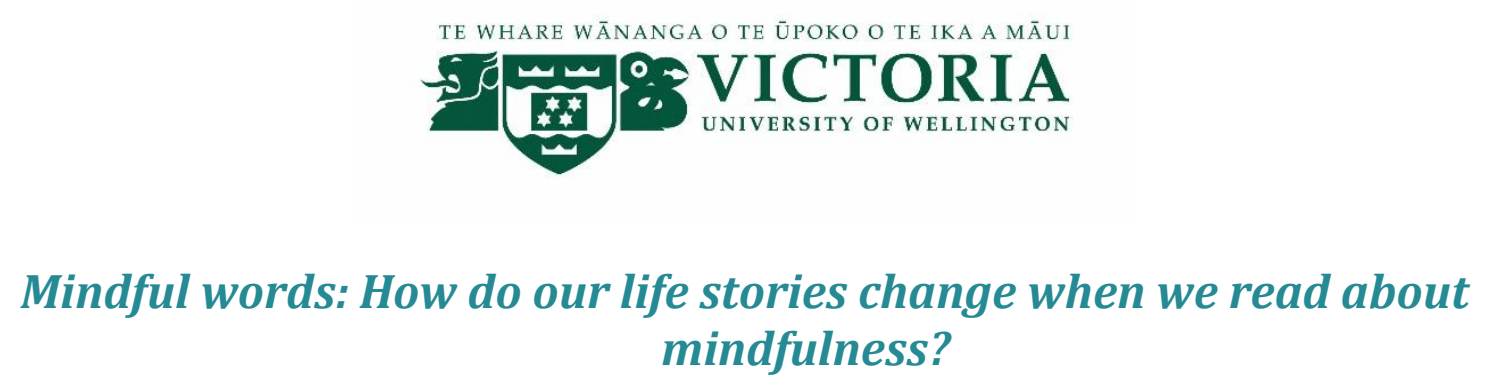

CONSENT TO TAKE PART IN THE STUDY

This consent form will be held for one year.

Researcher: Julia Watkin, School of Education, Victoria University of Wellington.

- I have read the Information Sheet and the project has been explained to me. My questions have been answered to my satisfaction. I understand that I can ask further questions at any time.

- I agree to read regular mindfulness blog posts, keep a journal, and take part in a discussion with the researcher.

I understand that:

- I may withdraw from this study at any point before 31 December 2017, and any information that I have provided will be returned to me or securely disposed of.

- $\quad$ The information I have provided will be securely disposed of on 30 April 2019.

- Any information I provide will be kept confidential to the researcher and the supervisor.

- The information will be used for a Master's thesis.

- My name will not be used in reports, nor will any information that would identify me.

- I would like a copy of my discussion transcript. $\quad \square$ Yes $\quad \square$ No

Name of participant:

Contact email:

Signature of participant:

Contact phone:

Date: 


\section{Appendix 4 Background narrative form}

\section{Participant background narrative}

The information provided here will be kept strictly confidential and used as a guidepost for the beginning of the journey. It will be written up in the final thesis as part of your personal story, but your real name and any identifying elements will not be included. You are free to write as much or as little as you like and only answer questions that you feel comfortable with.

Name Age

Ethnicity Occupation

Where do you come from and live now?

What is your understanding of what mindfulness is and how you become mindful?

Have you ever meditated or practiced mindful breathing techniques? Yes / No

If yes, what did you do, how often and do you practice now? 
Are you a reader? Yes / No

If yes, what content do you read/engage with (news/social media/websites/books etc.), how often, and how does it make you feel?

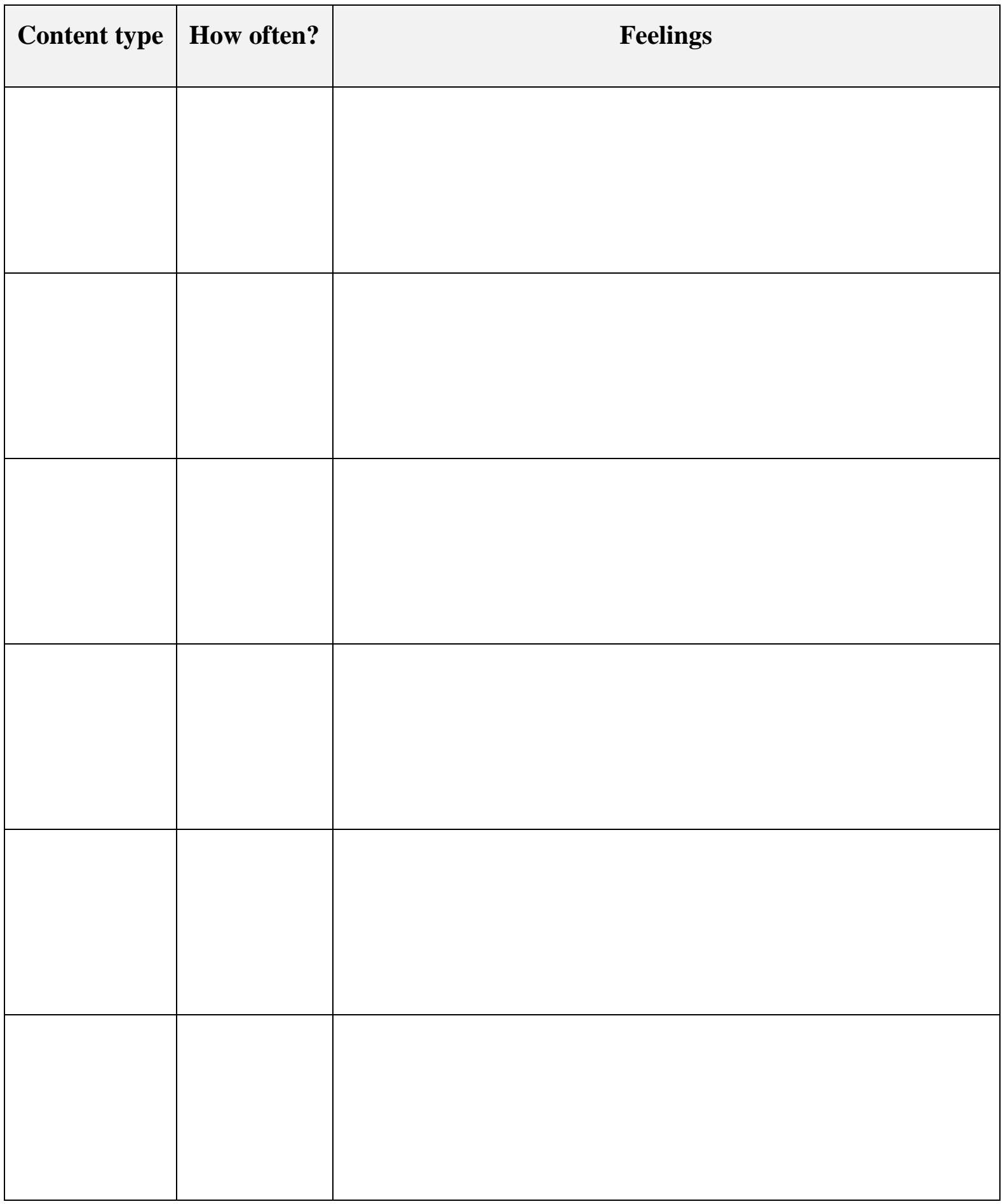


This is your space to tell me your story. You are welcome to use these questions as a guide, or just write what you feel is relevant. Who are you? What is your personality? What drew you to this research project? What is your current life situation? What are you happy with and what are you struggling with? In what areas do you think your quality of life could be improved? 
Appendix 5 Closing narrative form

\section{Participant closing narrative}

The information provided here will be kept strictly confidential and used as a guidepost for the end of the project journey. It will be written up in the final thesis as part of your personal story, but your real name and any identifying elements will not be included. You are free to write as much or as little as you like and only answer questions that you feel comfortable with.

Name

Your real name won't be used in the thesis, so what would you like your thesis name to be?

Has your understanding of what mindfulness is and how you become mindful changed? Y / N Please explain 
What content do you read/engage with (news/social media/websites/books etc.), how often, and how does it make you feel? Has this changed?

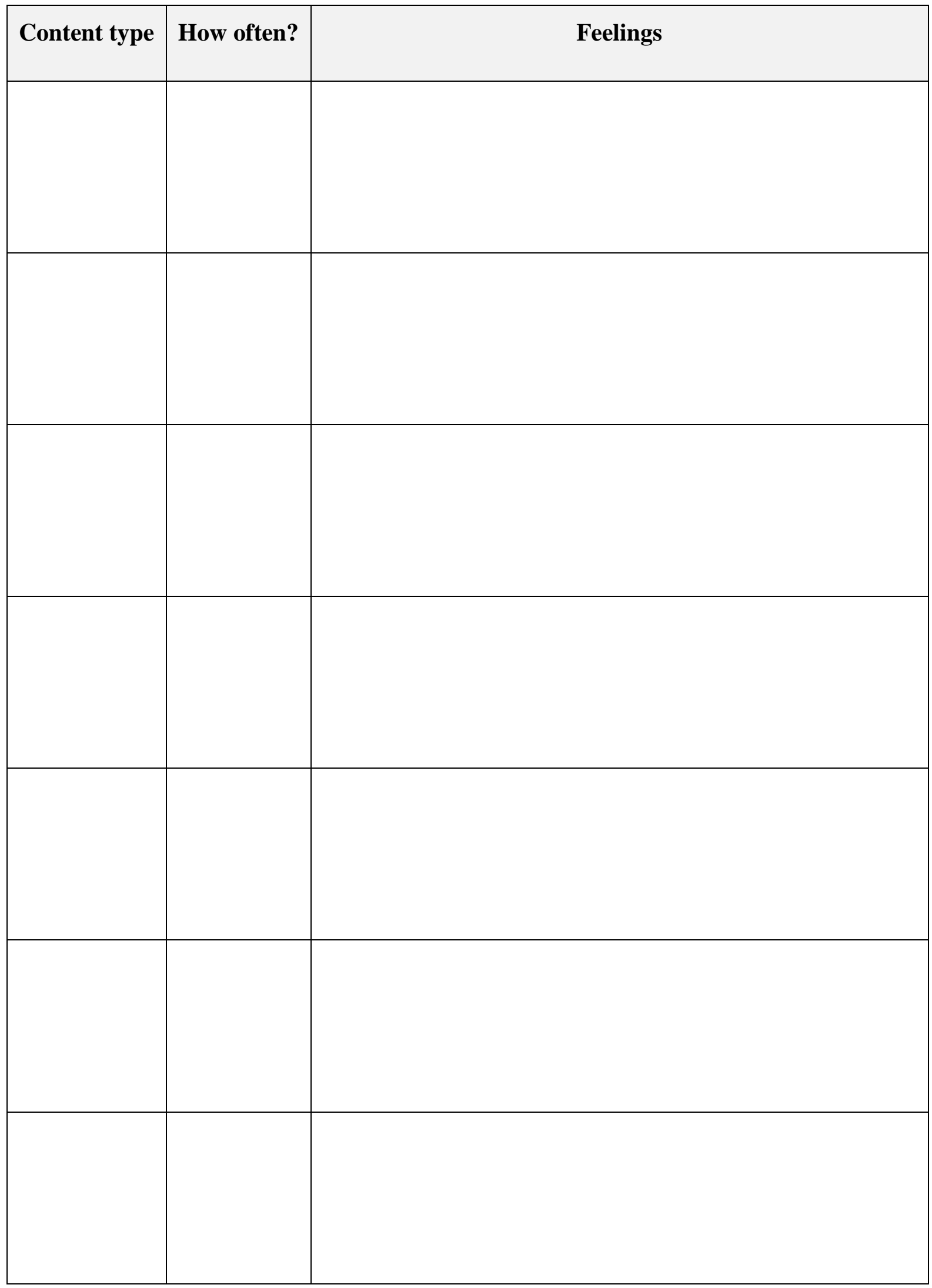


This is your space to tell me your story. You are welcome to use these questions as a guide, or just write what you feel is relevant. You don't need to repeat what you've written in your blog post reflections. A general debrief of the project, as a whole, would be wonderful. How are you feeling at the conclusion of the project? Has anything that you've read over the past three weeks really struck a chord with you? Have you made any changes in your mind or your life? If so, do you think they'll be sustainable? Or was reading just not enough to prompt meaningful change? Let me know your thoughts. 

